
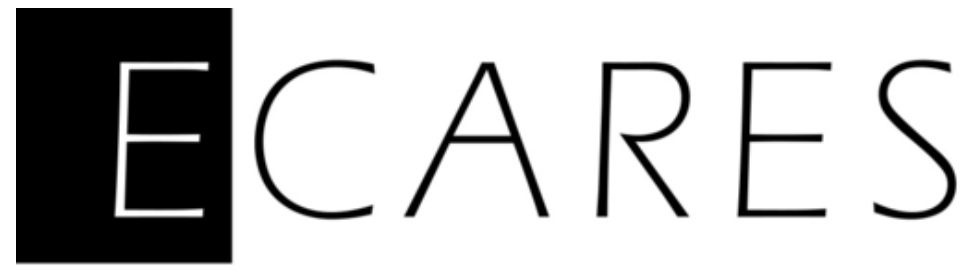

\title{
On the Political Economy of Industrial, Labor and Social Reforms as Complements
}

\author{
Antonio Estache \\ SBS-EM, ECARES, Université libre de Bruxelles \\ Renaud Foucart \\ SBS-EM, ECARES, Université libre de Bruxelles
}

May 2018

ECARES working paper 2018-13

ECARES

ULB - CP $114 / 04$

50, F.D. Roosevelt Ave., B-1050 Brussels BELGIUM

www.ecares.org 


\title{
On the political economy of industrial, labor and social reforms as complements*
}

\author{
Antonio Estache ${ }^{\dagger} \quad$ Renaud Foucart ${ }^{\ddagger}$
}

May 17, 2018

\begin{abstract}
We study the coordination between industrial, labor and social policy when voting determines policy choices. Firms choose to invest in either an old or a new sector. Most workers have skills constraining them to work in the old sector. A minority of workers are more productive in the new sector, and choose to be active where they expect a higher wage. Aggregate surplus is higher if firms invest in both sectors and workers are employed where they are the most productive. We identify conditions for such a modernized economy to develop. First, any labor policy must give workers enough bargaining power to have incentives to find the right job. Second, for an industrial policy to stimulate the new sector, a social policy involving both workers and firms must compensate the losers of modernization. Third, policies must be delegated to a social planner able to commit to the joint implementation of reforms and transfers.
\end{abstract}

JEL: D4, D72, J3, L1, L52

Keywords: bargaining power, industrial policy, voting

${ }^{*}$ We are grateful to Gani Aldashev, Micael Castanheira, Alexandre de Corniere, Bruno Decreuse, Mathias Dewatripont, Victor Ginsburgh, Paul Klemperer, and André Sapir for useful comments and discussions.

$\dagger$ ECARES, Université libre de Bruxelles (aestache@ulb.ac.be)

‡University of Nottingham Business School (renaud.foucart@nottingham.ac.uk) 


\section{Introduction}

Since the beginning of the Great Depression, industrial policy has returned to the political ${ }^{1}$ and academic $^{2}$ agenda as a solution to lasting reductions in productivity and persistently high unemployment in many OECD countries. Discussions generally emphasize the importance of identifying the sectors which will accelerate growth (Rodrik, 2009; Aghion et al., 2015). Every country seems to want to have a booming high-tech sector to replace an aging traditional industrial one. Debates also highlight the need to better match industrial policy with labor reforms designed to increase the incentives of workers to upgrade their skills and the scope for employers to make the most of the skill mix available. However, the political risks associated with the transitional costs of industrial and labor policy reforms as well as the role of social policies in this context are often ignored.

In this paper, we claim that a better coordination with labor and social policies is necessary for effective industrial policies. We first show that if labor policies do not allow workers to receive a sufficiently high share of the production surplus, economic modernization will not arise without further intervention. In practice, this is one of the potential roles for profit sharing rules. ${ }^{3}$ Second, for a given level of bargaining power, the government has to be able to commit to a social policy if the modernization of the economy is to be supported by a majority of voters. This could be implemented by the adoption of a restructuring fund similar to those adopted to support the banking sector restructuring after 2008. ${ }^{4}$ Third, this social policy has to combine an active support to the new sectors with transfers to the older workers losing from the modernization of the economy. This requires an explicit effort to target the allocation of resources. To do this targeting well, the information is usually relatively easily available. For instance, to identify the regions and sectors needing support, the European Commission produces detailed ex-ante regional and sectoral profiles which are also used to assess the effectiveness of its policies ex post. ${ }^{5}$

\footnotetext{
${ }^{1}$ In its 2014 guidelines ("For a European Industrial Renaissance,” European Commission, Brussels, 22.1.2014) the European Commission insists on the importance of a public policy favoring new sectors and innovations. Similarly the US and Japan witness heated debates about building a more pro-active industrial policy and using public intervention to favor some sectors of the economy (See for instance "The global revival of industrial policy", The Economist, August, 5, 2010 or "Trump aims for an industrial policy that works for America;" Rana Foroohar, Financial Times, May 7, 2017.)

${ }^{2}$ See for instance Hodler (2009), Cerqua and Pellegrini (2014), Alder et al. (2016), and Criscuolo et al. (2016)

${ }^{3}$ In the industrial relation literature, profit sharing is often seen as a cost effective and flexible way for employers to move to above market "efficiency wages" in order to attract and retain skilled labor or as a way to motivate workers to work more diligently and effectively towards organizational goals (see Kruse et al., 2010 and Baghdadi et al., 2016).

${ }^{4}$ In 2011, Germany adopted a Restructuring Fund, financed by the banking industry via an annual bank levy. Its assets have been used to restructure and reorganize systemically important banks in difficulty. A similar fund (the Fund for Orderly Bank Restructuring) was put in place as early as 2009 in Spain with a view to smooth the transition to a restructured banking industry but with direct contributions from the public sector.

${ }^{5}$ The European Social Fund created in 1957 by the European Union has been used to smooth a wide range of
} 
Our results are based on a model with two sectors, an old one and a new one. Production is the result of an employer being matched with one or more workers. A majority of workers has skills compatible with the old sector only, while a minority has the choice between being active in the old or in the new sector, and is more productive in the latter. The minority worker has more choice because she has only recently joined the labor market with the benefit of new skills acquired through education or training. Firms choose to be active in the sector in which their expected profit is higher. A worker of the minority type joins the new sector if she can expect to bargain a higher wage there. For a given bargaining power, wages depends on two elements: the productivity of the workers and the competition between firms in a sector. The more firms are present in a sector, the more they compete for workers, and the higher wage a given worker receives.

As fewer workers have skills compatible with the new sector, those workers trade off a higher productivity in this sector and a lower share of the surplus they generate. Workers' bargaining power must thus be high enough to motivate them to choose the sector in which they are the more productive. Firms choose in which sector to be active. For a given bargaining power, they are unambiguously better off by offering a more diverse production, as long as workers choose the sector in which they are the most productive. However, if workers' bargaining power is too low, firms won't invest in the new sector, because they don't expect enough workers with the corresponding skills to join this sector. We show that insufficient bargaining power for workers may lead to an equilibrium in which no sectoral diversity is offered, while there exists a bargaining power such that all workers and firms would be better off.

As identifying policies modifying bargaining power is both a complex and politically sensitive issue, we turn to the electoral system to see how a democratically chosen industrial policy can help solving the inefficiencies identified in the basic model, for a given bargaining power. As before, workers and firms decide in which sector to be active. However, before that, voters simultaneously choose with a majority rule an industrial policy and the size of government. The industrial policy consists in sector-specific corporate taxes or subsidies. The size of government corresponds to a level of public good to be financed through tax. Without social policy, we constrain this tax to be linear and independent of the type of worker. We find that the political equilibrium may actually lead to a lower aggregate surplus than without public intervention. As workers of the majority have the most to lose from a diverse production structure, they are likely to protect the old sector, even if it means having to subsidize the younger workers through taxes and the provision of a public

transitional costs resulting from the decision to stimulate economic and political convergence. Since 2007, its focus has been on human capital enhancement. The success rate of its intervention has been however been less than 50\%, illustrating how difficult the implementation and effective targeting of social policies can be in practice (ICF, 2015). 
good. The industrial policy determined by an electoral system decreases the size of the new sector and - unless the public good is valued a lot and the increase in the aggregate wages in a diverse equilibrium is high enough - often totally impedes its emergence.

We then consider the impact of interpersonal transfers as a way of increasing the political support for welfare enhancing policies. A key assumption is that the result of the vote is a commitment to implementing the joint social and industrial policy for a given bargaining power. In particular, the industrial policy cannot be reverted by a subsequent vote. We find that in a number of cases a social policy transferring wealth to the older workers, in exchange for their support to the new industry, can be implemented. If transfers are also possible between firms and workers, a democratic process always implements the highest possible aggregate output.

\section{Related literature}

The idea that the bargaining power of workers determines the quality of the matching on the labor market and that giving more incentives for workers to find the best jobs may lead to the creation of better jobs comes back to at least Albrecht and Axell (1984). The point that increasing the minimum wage, unemployment benefits or workers' outside option may increase the quality of jobs by inducing workers to search has been made by Marimon and Zilibotti (1999) and Acemoglu (2001). In related models, Shimer and Smith (2001) and Wilemme (2017) suggest that some workers should be subsidized and others taxed to find the job that corresponds the best to their skills. While we do not explicitly model the search process, the logic behind our workers' incentives is similar. The difference between our approach and those models is that we consider investments on the firms' side, so that the better jobs can actually lead to higher aggregate productivity.

Our results are indeed driven by the investment decisions of firms: too high a bargaining power for firms deters them from making the right investment. This idea contrasts with the classic holdup problem where a high bargaining power for workers deters the employers to invest enough and therefore leads to suboptimal productivity (Acemoglu and Shimer, 1999). The intuition behind the benefits from higher bargaining power for workers is reminiscent of Farrell and Gibbons (1995), who show that buyers are willing to better communicate their preferences to sellers if their bargaining power is sufficiently high. Our results also relate to another ex ante investment problem documented by Gall et al. (2006), where limits in the allocation of surplus within firms may either hinder the investment in human capital from workers, or generate a mis-allocation of employers to employees.

We are interested in the failure of the market to supply the right diversity of jobs. To clearly 
identify this relationship, we rule out the possibility of a general scarcity of jobs and therefore assume firms are able to hire several workers with constant returns to scale. In that sense, our model is very close to Albrecht and Axell (1984). By contrast, the assumption of a limited capacity of firms to hire is key to understanding many of the important results in search theory (Hosios, 1990; Mortensen and Pissarides, 1994, 1999), where there exists a trade-off between the resources used to advertise jobs (too many vacancies) and the costs of leaving workers unemployed (not enough vacancies).

We focus our attention on the horizontal part of skills differentiation: to make each worker be employed where she is the most efficient. The importance of this horizontal component has been documented by Papageorgiou (2014), who shows that for a representative sample of the US population, the data "favors the model of comparative advantage as opposed to the one-dimensional model of ability, which is most often used in the literature" (p.2). Previous research also insisted on the importance of horizontal matching between the skills of workers and the needs of firms (Helsley and Strange, 1990; Hamilton et al., 2000; Brueckner et al., 2002; Castanheira and Siotis, 2004). In our setting, an important constraint for employers is that, by choosing a sector, they have to make an ex ante (costless) investment that restrains their hiring possibilities. Our definition of a mismatch therefore corresponds to a worker employed in a sector in which she is not the most productive. This contrasts with recent attempts to identify mismatched workers as searching in a sector with an insufficient number of jobs (Şahin et al., 2014). In our setting, if all workers search for the same type of jobs and are immediately employed, they may still be mismatched.

We see our model of industrial policy as a complement to Aghion et al. (2015). They show that the role of industrial policy should be to motivate firms to be active in the same "high growth" sector, and therefore innovate "vertically" through competition. The idea is that supporting innovation of firms in different sectors would give each of those firms too high a market power. In our framework, it is also the existence of a too high market power of firms - but this time on workers - that can hinder the development of a more efficient production structure. Hence, an efficient industrial policy corresponds to inducing more firms to join the "high growth" sector, in order for them to compete more for workers and make them join this sector. Our approach also relates to Arkolakis (2016), in which firms have to pay a "penetration cost" to reach customers. In our setup, the difficulty for firms is to be able to attract the right workers.

Our model also relates to the idea that lobbies can create political barriers that slow down innovation, as empirically shown by Comin and Hobijn (2009). The idea that in a political process a majority of incumbents may block an innovation that increases aggregate welfare has been devel- 
oped by Krusell and Rios-Rull (1996). In their model with dynamic production, voting and skills training, the government has two choices: to block innovations or not to regulate at all. In their conclusion, the authors note that a combination of pro-innovation policy together with as compensation to the agents who lose might attract a majority of voters. We claim to provide conditions for such compensations to be implemented, as well as a rationale for why they are not often observed in practice: the need for a joint commitment on social and industrial policy. Saint-Paul (2002) shows that a majority of workers could politically block job creating labor market reforms, as workers in older industries face a tradeoff between the duration of employment and job creation. A related tradeoff is studied by Decreuse and Van Ypersele (2011), who study the interaction of rigidities in the labor and in the housing market.

\section{The basic model}

The economy is composed of two groups. The first group is a continuum of mass 1 of workers, with an exogenous share $\alpha$ of type $a$ and $1-\alpha$ of type $b$. We assume a strict majority of workers are of type a, $\alpha \in\left(\frac{1}{2}, 1\right)$. The share of workers of each type is common knowledge and the types are perfectly observable. The second group is composed of $M$ identical employers, who endogenously decide to offer jobs in sector $A$ or $B$ at no cost. The resulting number of employers in each sector are $m_{A}, m_{B}$, with $m_{A}+m_{B}=M$. An employer can be matched with more than one worker, but a worker can only work for one employer. We assume constant returns to scale, and workers and firms active in a small open economy not influencing the world prices by its production structure.

\subsection{Matching surplus}

The surplus generated by a worker of type $\theta \in\{a, b\}$ in sector $\chi \in\{A, B\}$ is denoted by $\sigma_{\theta \chi}$. A worker of type $a$ is only able to work in the "old" sector $A$, in which she generates a surplus equal to $\sigma_{a A}>0$, while $\sigma_{a B}=0$. A worker of type $b$ can work in both sectors, and generates a surplus in the "new" sector $B$ strictly higher than the one she generates in sector $A, \sigma_{b B}>\sigma_{b A}>0$. This aims at representing a majority of workers with older qualifications, already trained for specific jobs (type $a$ ), and workers arriving on the market, who can choose to train either for an old sector $A$ or an innovative sector $B$, but not for both.

A worker $i$ entering a given sector $\chi$ is randomly matched with a firm $j$ active in this sector. She then bargains a wage with the firm $j$, with bargaining power $\beta \in(0,1)$, and can threaten to work for another firm also active in sector $\chi$. A key assumption of the model is that the specialization of 
a worker is a commitment: a worker of type $b$ choosing sector $B$ is only productive in this sector, and cannot threaten to move back to sector $A$. The minimum number of employers active in a sector for a strictly positive wage to be paid is thus 2 , as else the worker would have no outside option.

Within a sector, firms are differentiated, so that there is a cost $s\left(m_{\chi}\right)$ to be matched with another firm in the sector, with $s>0, s^{\prime}<0$ and $s^{\prime \prime}>0$. We see three main drivers to such differentiation. The first one is geographical differentiation: the more firms are active in a sector, the smaller the travel cost to work to the second nearest firm. The second is horizontal differentiation within a given sector. Workers may have some preferences for a type of job. Finally, employers provide human capital to workers, and part of this human capital is firm-specific (see for instance Acemoglu and Pischke, 1999 and Silos and Smith, 2015). Only part of the production value can thus be taken to the next firm. We show in the Appendix how two standard models of monopolistic competition (a Salop circle and a sequential search model) give a micro-foundation for the function $s\left(m_{\chi}\right)$.

\subsection{The worker problem}

Within each sector, we focus on firms offering identical wages to identical workers. Consider a symmetric wage $w_{\theta \chi}$ for a worker of type $\theta \in\{a, b\}$ in sector $\chi \in\{A, B\}$. The worker could get the same wage in another firm, but has to bear an expected cost $s\left(m_{\chi}\right)$, so that her outside option is equal to $w_{\theta \chi}-s\left(m_{\chi}\right)$. She can thus bargain a wage equal to this outside option plus a share of the difference between her productivity and her outside option,

$$
w_{\theta \chi}=\left(w_{\theta \chi}-s\left(m_{\chi}\right)\right)+\beta\left(\sigma_{\theta \chi}-w_{\theta \chi}+s\left(m_{\chi}\right)\right),
$$

so that at the symmetric equilibrium,

$$
w_{\theta \chi}=\sigma_{\theta \chi}-\frac{1-\beta}{\beta} s\left(m_{\chi}\right) .
$$

For a worker of type $a$, there is no other strategic decision than wage bargaining. Additionally, a worker $i$ of type $b$ must decide in which sector to be active. This decision $\delta_{i}\left(m_{A}, m_{B}\right) \in\{A, B\}$ is a mapping from the number of firms active in each sector $m_{A}, m_{B}$ to a choice of sector $j \in\{A, B\}$. We denote by $\delta$ the vector of all the sectors chosen by individuals of type $b$.

Denote by $\lambda=\frac{1-\beta}{\beta}$ the relative bargaining power of the firms with respect to the one of the workers. For a given number of employers active in each sector, it is possible to determine whether workers are active in one or both sectors. Sector $j$ is a best response for a worker of type $b$ if it is 
the sector that brings the highest wage $\delta=\arg \max _{\hat{\delta} \in\{A, B\}} w_{b \hat{\delta}}\left(m_{\hat{\delta}}\right)$.

Lemma 1 If enough firms are active in the new sector $B, \sigma_{b B}-\sigma_{b A}>\lambda\left(s\left(m_{B}\right)-s\left(m_{A}\right)\right)$, each worker is employed where she is the most productive.

The formal proof is in Appendix. This condition states that a worker of type $b$ chooses her best sector if and only if the gain in productivity is sufficiently high to compensate for the loss in the wage she can bargain because of the higher market power for the firm. Hence, the more firms are active in sector $B$, the more a worker of type $b$ is willing to join this sector.

Two of our assumptions are crucial to this result. First, we assume that once a worker has chosen sector $B$, she cannot move back to sector $A$. What we need for our results to hold is that it is sufficiently more costly to switch sectors than to switch employer within a sector. If these costs were similar, a worker of type $b$ would never receive a lower wage in sector $B$ than in sector $A$, if working in sector $A$ is the outside option. We believe that this assumption is however in line with the idea that there is a cost to specialization and that part of the human capital is not only job-specific but sector-specific. Second, we assume constant returns in both sectors. If the first unit produced in sector $B$ were much more valuable than the subsequent ones, it would be easier to attract workers in this sector.

\subsection{The employer problem}

The $M$ employers simultaneously choose in which sector to be active. An employer's strategy $\mu \in\{A, B\}$ is a mapping from the best response of workers of type $b, \delta\left(m_{A}, m_{B}\right)$, and the number of firms active in each sector $m_{A}, m_{B}$ to a sector $A$ or $B$.

If workers choose the sector in which they are the more productive, $\delta_{i}=B$ for all worker of type $b$, that we denote by abuse of notation $\delta=b$, a firm active in sector $A$ makes an expected profit equal to

$$
\pi_{A, \delta=B}=\frac{\alpha}{m_{A}} \lambda s\left(m_{A}\right)
$$

and similarly an employer active in sector B makes an expected profit $\pi_{B, \delta=B}=\frac{1-\alpha}{m_{B}} \lambda s\left(m_{B}\right)$. Hence, profit in sector $A$ increases with the share of workers of type $a, \alpha$, with the relative bargaining power of employers $\lambda$, and decreases with the number of employers in sector $A$.

For a given vector of workers' decisions $\delta$, it is possible to characterize the solution to the employer problem by letting firms choose to be active in the sector that gives them the higher expected profit. 
Lemma 2 If all workers are active in the sector in which they are the more productive $(\delta=B)$, the share of firms active in the old sector $A$ is comprised between $1 / 2$ and the share of the population of type a, $\alpha$, so that $m_{A}(\delta=B) \in(M / 2, \alpha M)$.

The formal proof is in the Appendix. There is always a strict majority of firms active in the old sector $A$. The reason is that, if the number of employers is equal in both sectors, the market power of employers in both sectors is also equal, so that the profit per worker is equal. As there are more workers in sector $A$, the profit is higher in this sector and it is a best response for a employer active in sector $B$ to switch to sector $A$. The proportion of firms in sector $A$ remains in equilibrium lower than the share of workers of type $a$ in the population. If a share $\frac{m_{A}}{M}=\alpha>1 / 2$ of the employers are active in sector $A$, the market power of employers is lower in this sector, so that the profit per worker is higher in sector $B$. As there are as many workers per firm in both sector, the profit is higher in sector $B$ and more employers join this sector. Hence, the equilibrium number of firms in sector $A$ is strictly comprised between $\frac{M}{2}$ and $\alpha M$.

If all firms make identical expected profit and workers of type $b$ work in sector $B$, the expected profit of employers is equal to $\pi_{\delta=B}^{*}=\frac{\alpha \lambda_{s}\left(m_{A}(\delta=B)\right)+(1-\alpha) \lambda_{s}\left(M-m_{A}(\delta=B)\right)}{M}$. If all workers choose to go to sector $A, \delta=A$, the expected profit of an employer is equal to $\pi_{\delta=A}^{*}=\lambda \frac{s(M)}{M}$. For a given $\lambda$, this profit is lower than when workers go to their best sector. Indeed, by being all active in the same sector, firms have a lower market power. This is the reason why firms benefit from sectoral diversity: it increases their market power, so that they can pay a worker less than its marginal productivity.

\section{Equilibrium without industrial policy}

A Nash equilibrium is a situation in which, for each employer, the profit $\pi$ is the maximum that can be obtained given the decision of other employers and of the workers,

$$
j=\arg \max _{\hat{j} \in\{A, B\}} \pi_{\hat{j}}\left(m_{A}, m_{B}, \delta\right)
$$

and for all workers of type $b$ the sector is the one that maximizes their expected wage given the number of firms active in each sector

$$
\delta_{i}=\arg \max _{\hat{\delta} \in\{A, B\}} w_{b \hat{\delta}}\left(m_{\hat{\delta}}\right)
$$


It is easy to see that the game suffers a potential coordination problem on the employers' side. If all firms are active in sector $A$ only, it remains an equilibrium to do so. Indeed, it is a best response for all workers of type $b$ to choose sector $A$. It is thus a best response for firms not to be active in sector $B$. However, all firms are better off if a share $m_{B}(\delta=B)=M-m_{A}(\delta=B)$ switches to sector $B$ and workers of type $b$ choose to work in this sector.

For this reason, we allow firms to coordinate on an equilibrium that is Pareto-dominant for them. This allows us to fully characterize the equilibrium.

Proposition 1 If the relative bargaining power of employers is sufficiently low, $\lambda<\lambda^{s}\left(m_{B}(\delta=\right.$ $B)$ ), there are jobs offered in both sectors, and workers of type $b$ work in the new sector B. Else, all active firms are in the old sector $A$.

The formal proof is in Appendix. This proposition constitutes the driving force behind all our results. Because a worker has to choose a sector, a worker of the minority type $b$ only enters her best sector $B$ if the expected wage in this sector is high enough. As fewer firms are active in sector $B$ than $A$ in a diverse equilibrium, it is only the case if workers' bargaining power is sufficiently high. Firms only offer jobs in both sectors if they expect workers to work in both sectors, this is if $\lambda$ is sufficiently low. We illustrate the equilibrium share of firms in sector $B$ on Figure 11 (in appendix). Up to $\lambda^{s}$, the share of firms active in sector $A$ is the solution to $m_{A}(\delta=B)$ found it lemma 2. For $\lambda>\lambda^{s}$, firms are active in sector $A$ only and $m_{A}=M$,

$$
m_{A}^{*}= \begin{cases}m_{A}(\delta=B) & \text { if } \lambda \leq \lambda^{s}, \\ M & \text { if } \lambda>\lambda^{s} .\end{cases}
$$

A perhaps surprising consequence of Proposition 1 is that an increase in workers' bargaining power could in some case be Pareto improving. We provide the proof and conditions for this to be the case in Appendix B. Whether reaching a collective agreement over a variable such as bargaining power is feasible in practice is however dubious. How does a policymaker exactly determine bargaining power, and how such a commitment can be made possible in a democracy are difficult questions. However, this simple model already allows us to make the following observation: in a world where governments often think that more flexible labor, in particular for younger workers, is part of the solution to a sustained growth, we show that such policies may actually go in the wrong direction. A highly productive economy needs to have high sectoral diversity. And this diversity increases costs for workers: those need to adapt their skill set to the new sectors. Unless they anticipate they can bargain high enough rents in new sectors, they won't incur these costs. 
The bargaining power is very different from a minimum wage or the level of firing costs. It is an exogenous parameter, constant for all matches. Hence, for a given disagreement point, a higher bargaining power increases the link between wages and productivity. For instance, in our model, introducing a minimum wage $\bar{w}$ would not give incentives to workers of type $b$ to move to sector $b$, quite the contrary as if workers of type $b$ end up being paid the minimum wage in sector $A$, it means that $\bar{w}>\sigma_{b A}-\lambda s\left(m_{A}(\delta=B)\right)$. The condition for workers to go to their most productive sector therefore becomes $\lambda<\frac{\sigma_{b B}-\bar{w}}{s\left(m_{B}(\delta=B)\right)}$. For a given $m_{A}(\delta=B)$, the condition is more restrictive. However, a minimum wage makes being active in a sector where it is binding less attractive to firms, so that $m_{B}(\delta=B)$ increases with $\bar{w}$, making the overall effect ambiguous.

We adopt in the next sections a political economy approach to model a more realistic way through which sectoral diversity can be achieved: industrial policy. We first study industrial policy in a world in which no direct transfers are possible among agents, but voters select a level of taxation that fund a public good. We then allow for different types of transfers.

\section{Voting on industrial policy}

We now take the bargaining power of workers $\beta$ as given, and discuss a more general framework in which tax rates and industrial policy are the result of a majority rule.

To do so, we add an initial stage to the game. In this initial stage, two political parties $l$ and $r$ offer a policy $\Psi_{j}=\left\{\tau, f_{A}, f_{B}\right\}, j \in\{l, r\}$ were $\tau$ is a linear tax rate on workers' income and $f_{A}$ and $f_{B}$ correspond to the industrial policy. The latter is modeled as sector-specific corporate taxes and subsidies - whether a firm active in a given sector $i \in\{A, B\}$ is taxed $\left(f_{i}<0\right)$ or subsidized $\left(f_{i}>0\right)$. In this section, we assume that there is no direct way to transfer wealth among workers, other than a proportional tax, common to all types of workers. The revenue of the personal income tax is used to finance the government, that we model as a level of investment in a public good. We also assume that industrial policy must be self-financed, so that firms can only be subsidized to the extent that the money comes from taxing the other sector. Both assumptions are meant to avoid the trivial result of tyranny of the majority, in which a majority of voters would tax the others their entire surplus as well as all the firms. In subsequent sections, we partly relax those assumptions by allowing for transfers if and only if they are unanimously accepted. The idea is then again that political parties make proposals involving transfers that can only be accepted if supported by all workers and firms. 
The precise timing is as follows:

1. Two parties offer a policy platform $\left\{\tau, f_{A}, f_{B},\right\}$.

2. Voters elect their preferred platform using a simple majority rule, ties are broken randomly.

3. Firms choose in which sector to be active and workers choose in which sector to work (as in Section 2).

The objective function of a party is to maximize its probability of being elected. The objective function of workers is to vote for the party that gives them the higher expected utility, given the expected equilibrium of the subgame studied in the above sections. Hence, as workers with older qualifications $a$ constitute a strict majority, it follows directly that both parties offer identical platforms in equilibrium, corresponding to maximizing the expected utility of the median voter, of type $a$.

Industrial policy modifies the choice of firms as defined in section 2.3. For any industrial policy $f=\left\{f_{A}, f_{B}\right\}$, the value of $m_{A}(f, \delta=B)$ if workers choose their most productive sector solves

$$
\frac{1-\alpha}{M-m_{A}} \lambda s\left(M-m_{A}\right)+f_{B}=\frac{\alpha}{m_{A}} \lambda s\left(m_{A}\right)+f_{A}
$$

The left-hand side of (6) is the expected profit of a firm active in sector $B$. This profit increases in the number of workers of type $b$ and in employers' relative bargaining power $\lambda$. It also decreases in the number of firms active in sector $B, m_{B}=M-m_{A}$. First, because the employers' share of the production has to be divided among more firms. Second, because the employers' share decreases when the sector is more competitive. Similarly, right-hand side of (6) is the expected profit of a firm active in sector $A$.

As in the case without industrial policy, workers are active in their most productive sector if the benefits from higher productivity of workers of type $b$ in sector $B$ more than compensate their lower market power in this sector:

$$
s\left(m_{A}\right)-s\left(M-m_{A}\right)<\frac{\sigma_{b B}-\sigma_{b A}}{\lambda} .
$$

A first observation is that it is always possible in theory to design a self-financing industrial policy such that workers are active in their most productive sector.

Lemma 3 There exists an industrial policy $\tilde{f}_{B}$, under the constraint $f_{A}=-\frac{m_{B}}{m_{A}} f_{B}$, such that for all $f_{B}>\tilde{f}_{B}$, workers are active in both sectors, and for all $f_{B}<\tilde{f}_{B}$ firms are only active in the 
old sector $A$. Such a $\tilde{f}_{B}$ is equivalent to a minimum number of firms active in sector $B, \tilde{m}_{B}$. For all $m_{B} \geq \tilde{m}_{B}$, there exists an industrial policy $f_{B}\left(m_{B}\right)$ that leads to the desired number of firms in sector $B$. There is no industrial policy that leads to $m_{B} \in\left(0, \tilde{m}_{B}\right)$.

The formal proof is in the Appendix. The above result implies that any number of firms in sector $B$ such that workers of type $b$ choose their most productive sector can be reached using industrial policy. It is also always possible to induce an equilibrium in which all firms are active in sector $A$. The only thing that is not possible is to induce a strictly positive number of firms in sector $B$ that is not high enough for workers of type $b$ to take a job in this sector. This lemma directly stems from (6) and (7). By identifying the minimum number of firms active in sector $B$ so that workers of type $b$ choose this sector, the corresponding industrial policy mechanically follows. The value of $\tilde{m}_{B}$ can be either higher or lower than the equilibrium value without industrial policy, but is never higher if this equilibrium value is strictly higher than zero. If firms are active in sector $A$ only without industrial policy $\left(\lambda>\lambda^{s}\right), \tilde{m}_{B}$ is higher than the equilibrium value of zero. However, for all values of $\lambda \leq \lambda^{s}, \tilde{m}_{B} \leq m_{B}(\delta=B)$, the market provides more firms in sector $B$ than what is necessary for workers of type $b$ to work in their best sector.

Define the utility function of a worker of type $i \in\{a, b\}$, quasi-linear in her wealth and increasing in a level of public good $G$, as

$$
u_{i}=w_{i}-T+v(G)
$$

with $T$ the total tax paid, and $v(G)$, with $v^{\prime}>0, v^{\prime \prime}<0$ the utility from the public good. Using the constraint that tax is linear and goes directly into the public good, (8) rewrites as

$$
u_{i}=(1-\tau) w_{i}+v\left(\tau\left(\alpha w_{a}+(1-\alpha) w_{B}\right)\right),
$$

where $w_{a}$ and $w_{b}$ denote the equilibrium wage of workers of each type, a function of sectoral diversity. As a majority of workers are of type $a$, the median voter is of this type. Hence, the chosen tax rate always corresponds to the preferences of a worker of type $a$. It solves

$$
\tau^{*}=v^{\prime-1}\left(\frac{w_{a}}{\alpha w_{a}+(1-\alpha) w_{b}}\right) \frac{1}{\alpha w_{a}+(1-\alpha) w_{b}} .
$$

From the above, we see that the sign of the relationship between $\tau^{*}$ and sectoral diversity is ambiguous. Two effects determine the tax level.

First, if there is sectoral diversity, the wage structure is more compressed: the difference be- 
tween the wage of workers of type $a$ and $b$ is smaller. The wage differential when all firms are active in sector $A$ corresponds to the difference in productivity. When firms are active in both sectors, this difference is lower (and possibly negative), but there is a difference in the market power of workers in both sectors. With firms active in both sectors, workers of type $a$ receive $w_{a}=w_{a A}=\sigma_{a A}-\lambda s\left(m_{A}\right)$ and workers of type $b w_{b}=w_{b B}=\sigma_{b B}-\lambda s\left(M-m_{A}\right)$. With firms active in sector $A$ only, workers of type $a$ receive $w_{a}=w_{a A}=\sigma_{a A}-\lambda s(M)$ and workers of type $b w_{b}=w_{b A}=\sigma_{b A}-\lambda s(M)$. The wage structure when firms are active in both sectors is more compressed if $\sigma_{b B}-\sigma_{b A}>\lambda\left(s\left(M-m_{A}\right)-s\left(m_{A}\right)\right)$, which is exactly the condition for $\delta=B$ to be the best response of workers of the minority type $b$ (see Lemma 1). The more compressed wage structure with two active sectors leads to a higher tax rate, because for each monetary unit gathered through taxation, a higher share comes from workers of type $b$, something that benefits the median voter (of type $a$ ).

Second, if the total wages are higher with firms active in both sectors, this implies that that the tax base is larger. As the marginal benefit from the public good is decreasing, it is possible that the median voter prefers a lower tax rate with firms active in both sectors than with sector $A$ only - which still provides her with a higher level of public good.

Of the determinants of the wages $w_{a}$ and $w_{b}$, the only endogenous parameter is $m_{B}$, with $m_{A}=M-m_{B}$. Thus, the tax rate that maximizes the utility of a worker of type $a$ can be expressed as $\tau^{*}\left(m_{B}\right)$. The utility of a worker of type $a$ choosing the tax level that maximize her utility can therefore be expressed as $u_{a}^{*}\left(m_{B}\right)$, where $m_{B}$ determines both the industrial policy $f_{B}\left(m_{B}\right)$, $f_{A}=-\frac{m_{B}}{m_{A}} f_{B}\left(\bar{m}_{B}\right)$ and $\tau^{*}\left(m_{B}\right)$. It is thus possible to characterize the political equilibrium.

Lemma 4 Denote by $f_{B}\left(m_{B}\right)$ the industrial policy that leads to $m_{B} \geq \tilde{m}_{B}$. Denote by $\bar{m}_{B}$ the value of $m_{B} \geq \tilde{m}_{B}$ that (locally) maximizes the utility of a worker of type a, with a tax rate $\tau^{*}\left(\bar{m}_{B}\right)$ as defined in (10). The political equilibrium $\psi=\left\{\tau, f_{A}, f_{B}\right\}$ is given by:

$$
\psi= \begin{cases}\left\{\tau^{*}\left(\bar{m}_{B}\right),-\frac{m_{B}}{m_{A}} f_{B}\left(\bar{m}_{B}\right), f_{B}\left(\bar{m}_{B}\right)\right\} & \text { if } u_{a}^{*}\left(\bar{m}_{B}\right) \geq u_{a}^{*}(0), \\ \left\{\tau^{*}(0), 0, f_{B}\left(\tilde{m}_{B}\right)-\varepsilon\right\}, \text { with } \varepsilon>0 & \text { if } u_{a}^{*}\left(\bar{m}_{B}\right)<u_{a}^{*}(0) .\end{cases}
$$

The formal proof is in the Appendix. As there is a majority of voters of type $a$, the political equilibrium corresponds to the preferences of these workers. The majority type compares two options. The first one is the absence of sectoral diversity, which can be enforced by making sure that not enough firms would enter sector $B\left(f_{B}=f_{b}\left(\tilde{m}_{B}\right)-\varepsilon\right.$, with $\left.\varepsilon>0\right)$ so that $m_{B}>0$ is not an equilibrium. In that case, the tax rate is $\tau^{*}(0)$. The second is a diverse production structure. 
In that case, there exists a local maximum of $a$ 's utility, that is reached with a number of firms $\bar{m}_{B}$ in sector B: conditional on firms being active in both sectors, this is the number of firm that maximizes a worker of type $a$ 's utility choosing the (locally) optimal tax rate $\tau^{*}\left(\bar{m}_{B}\right)$. The political equilibrium is thus the policy $\psi$ that maximizes the utility of workers of type $a$ : either firms active in sector $A$ only or a number of firms $\bar{m}_{B}$ in sector $B$.

Proposition 2 The political equilibrium has the following properties:

1. Voters choose an industrial policy that favors sector A, so that the new sector $B$ does not develop, unless there exists a number of firms $m_{B} \geq \tilde{m}_{B}$ in sector $B$ such that the sum of all workers wages is higher with two active sectors than with sector A only, and workers value the consumption of the public good sufficiently.

2. In the particular cases of linear random sequential search and of linear transportation costs in a Salop model, voters always choose fewer firms in sector B than in a market without public intervention.

The formal proof is in Appendix. For voters to support the new sector, it must be the case that the sum the wages of workers of all types is higher when firms are active in both sectors than when they are active in sector $A$ only. Else, an industrial policy that allows for a sector $B$ to be active would always be rejected as such a policy gives the median voter both a lower wage and a lower tax base.

The sum of all wages is not a binary value, depending on whether firms and workers are active in both sectors or not. It depends both on the (binary) total productivity and on the (continuous) share of the production retained by workers in each sector. Indeed, the number of firms active in sector $B$ - when it is comprised between the minimum for sectoral diversity to be an equilibrium $\tilde{m}_{B}$ and $M / 2$ - modifies both the wage distribution and the aggregate wages. If there exists at least one value of $m_{B} \geq \tilde{m}_{B}$ such that having firms active in both sectors increases aggregate wages, then there is a trade-off for the median voter. On the one hand, she receives a lower wage. On the other hand, the tax base is larger, so that there can be a higher production of public good for a similar tax rate. A necessary - but not sufficient - condition for the median voter to accept a lower salary is that the second effect dominates. If this effect is sufficiently large, and the median voter values sufficiently the production of the public good, she may accept some sectoral diversity even if it decreases her own wage. In this section, the production of the public good through a linear personal income tax is the only way to transfer resources, as direct interpersonal transfers or transfers from firms - are not allowed. 


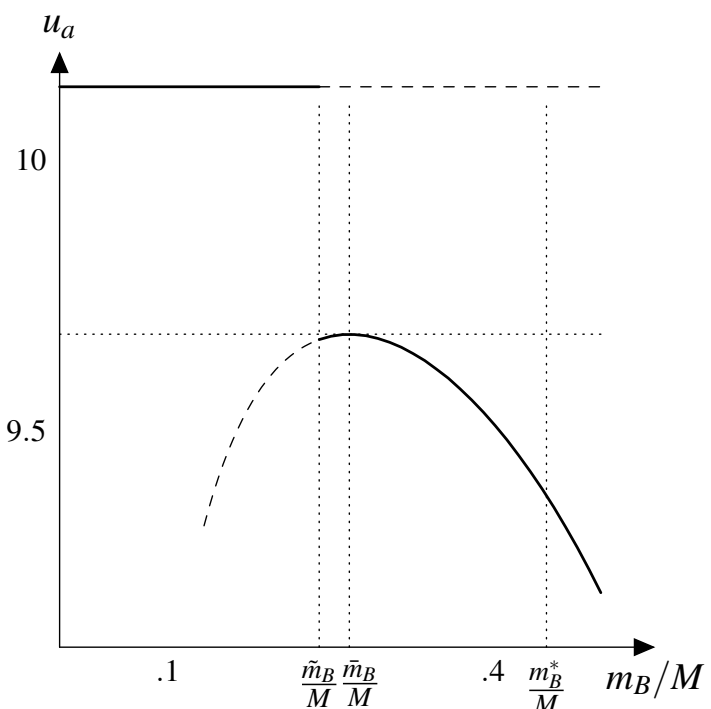

Figure 1: Utility of a worker of the majority type $a$

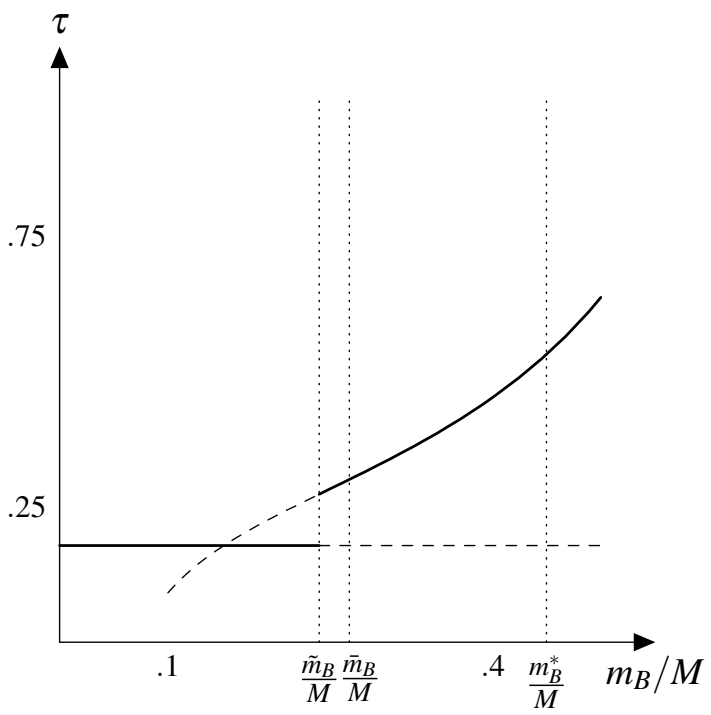

Figure 3: Equilibrium tax rate $\tau$

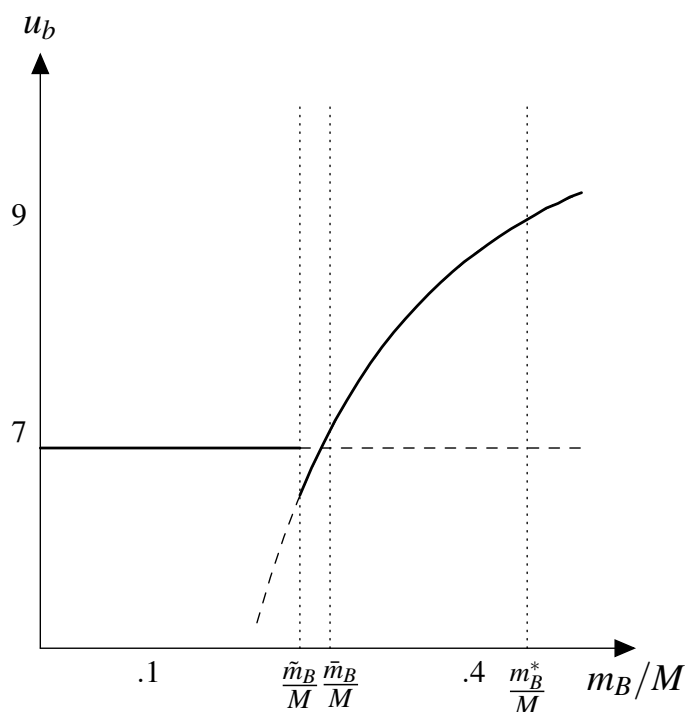

Figure 2: Utility of a worker of the minority type $b$ $U, W$

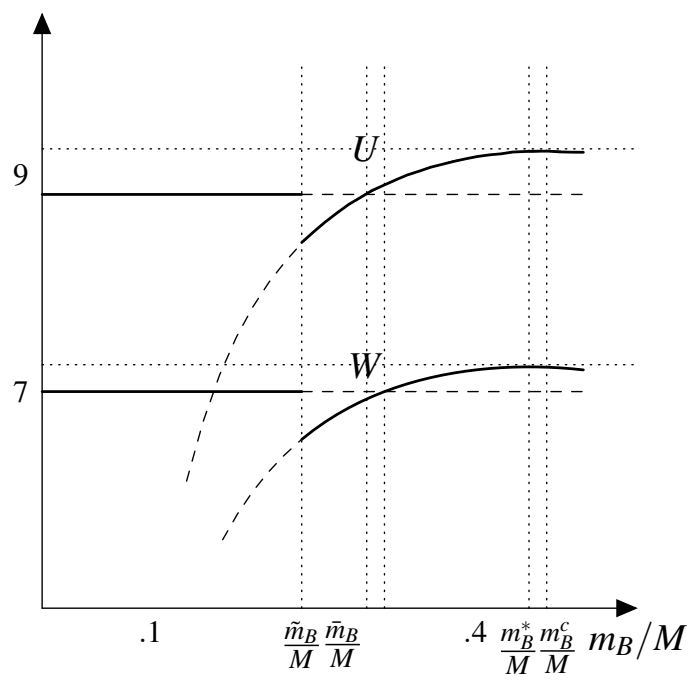

Figure 4: Aggregate worker utility and aggregate wages

Political equilibrium, $\lambda=.35, M=15, s=60, \sigma_{a A}=\sigma_{b B}=10, \sigma_{a B}=8, \sigma_{b A}=6, \alpha=.6$, $v(G)=2 \sqrt{G}$. 
To see this, consider the illustration on Figures 1-4. The parameters chosen for this example are such that, without industrial policy $\left(f_{B}=0\right)$, firms are active in both sectors $(\delta=B)$. The equilibrium share without industrial policy $\frac{m_{B}(\delta=B)}{M}$ (corresponding to the results in section 3 ) is depicted on all figures as $m_{B}^{*}$, and represents around $45 \%$ of the firms, while workers of type $b$ are $40 \%$ of the population. The minimum share of firms for workers of type $b$ to choose sector $B, \frac{\tilde{m}_{B}}{M}$ is however much lower, around 24\%. Figure 1 represents the utility of a majority worker for given shares of firms in the minority sector $B$. The part to the left of $\frac{\tilde{m_{B}}}{M}$ represents the case with firms in sector $A$ only (only $m_{B}=0$ constitutes an equilibrium), while the part to the right of $\frac{\tilde{m}_{B}}{M}$ represent cases where an equilibrium with sectoral diversity exists. Conditional on $m_{B} \geq \tilde{m_{B}}$, there exists a number of firms in sector $B$ that constitutes a local maximum for the workers of the majority denoted by $\bar{m}_{B}$. In this case however, we see that workers of the majority type are always strictly better off without sectoral diversity, as $u_{a}(0)>u_{a}\left(\bar{m}_{B}\right)$.

Hence, the political equilibrium is to set $f_{B}<\tilde{f}_{B}<0$, sufficiently small for no firm to be active in sector $B$, and all workers to stay in sector $A$. We see on Figure 2 that by doing so, workers of type $a$ constrain the surplus of workers of type $b$ to be lower than if firms are active in both sectors. We also see on Figure 3 that having firms active in both sectors would lead to a higher taxation rate, because workers of type $a$ would share the burden with workers of type $b$. Figure 4 shows that, because of these two effects, there are values of $m_{B}$ such that aggregate wages $W$ and aggregate utility $U$ are higher when firms are active in both sectors. The first condition of Proposition 2 (higher aggregate wages) is thus fulfilled, but not the second one. The taste for the public good is not strong enough for the higher aggregate wages of workers to translate into a political equilibrium. The political equilibrium is such that an economy that would have a diverse production structure without industrial policy remains non-diversified. A majority of workers prefers to support the old industry, at the cost of a lower production of the public good and lower aggregate wages, because they cannot get a sufficiently high share of the newly created wealth. It is possible to show that, by increasing the taste for the public good, $v(g)$, the political equilibrium could switch to a strictly positive share of firms in sector $B$.

With higher valuation for the public good, it is also in theory possible that the share of firms in sector $B$ that maximizes the utility of workers of type $a$ is higher than without industrial policy, $\bar{m}_{B}>m_{B}^{*}$. To see this, consider a valuation for the public $\operatorname{good} v(G)=g \sqrt{G}$ as in the examples, but with $g \rightarrow \infty$. In this case, the only element a worker cares about is the public good, so that $\tau^{*}\left(m_{B}\right) \rightarrow 1, \forall m_{B}$. It is therefore straightforward that the utility maximizing share of firms in sector $B$ is the one that maximizes the aggregate wages, which can in theory be higher than $\frac{m_{B}^{*}}{M}$. 
In the special cases of linear random sequential search and linear transportation costs on a Salop circle however, it is possible to show (see proof of Proposition 2) that $\frac{m_{B}^{*}}{M}$ is precisely the value that maximizes aggregate wages when there is sectoral diversity. Hence, even in the most extreme case where workers care only about the public good, they never choose more firms in sector $B$ than in the market equilibrium without public intervention.

Our assumption of linear returns in both sectors is an important driver of the result of a majority of workers opposing the presence of two active sectors. If workers of type $a$ would suffer from the competition of workers of type $b$ in sector $A$ - for instance through lower marginal productivity they would have more incentives to support the existence of a sector $B$. While decreasing returns and competition for jobs are certainly important in practice, what we need for our results is that workers of the majority type have more to lose from the decrease in the number of employers in their sector than from the lower demand for jobs in this sector.

\section{Industrial policy with monetary transfers among workers}

Consider now the possibility of monetary transfers among workers. The question of how such transfers are possible is complex, as it involves strong commitment from a social planner. One way of doing so is to consider an external player, acting like the head of a household in Bergstrom (1989) offering a transfer between workers of a certain types and an industrial policy, to be implemented under unanimity rule only, before the choice of linear taxation is made by the median voter. We make the following assumption on the objective function of such a head of the household: she must offer a deal that is Pareto efficient given the expected equilibrium tax rate and production structure in the subsequent subgame. As the head of the household can offer any interpersonal transfer and utility is quasi-linear in money, the only Pareto-efficient policy is the one that maximizes aggregate utility.

The initial choice of a joint social and industrial policy needs to be a credible commitment, as letting the median voter change the industrial policy after the fact would make the equilibrium we study in this section disappear. For a given industrial policy, we let tax rates be chosen by the median voter as before. Letting the tax rate be the result of a political consensus would even slightly increase the range of political possibilities, as it would allow for higher total wages. We however focus here on the possibility to commit on industrial policy and interpersonal transfers only.

We denote the social policy by $t=\left\{t_{a}, t_{b}\right\}$, with $\alpha t_{a}=(1-\alpha) t_{b}$ and $t_{i}$ the (possibly negative) 
monetary transfer received by a worker of type $i \in\{a, b\}$.

The modified timing is as follows:

1. The social planner offers a social and industrial policy $\left\{t, f_{A}, f_{B}\right\}$

2. If all workers accept the offer, the policy is implemented. Else, workers play the game described in Section 4

3. Two parties offer a policy platform $\tau$.

4. Voters elect their preferred platform using a simple majority rule, ties are broken randomly.

5. Firms choose in which sector to be active and workers choose in which sector to work.

Proposition 3 When unanimous transfers are possible between workers and there exists a value of $m_{B}$ such that the aggregate worker utility is higher with two active sectors than than with sector A only, voters choose an industrial policy that favors sectoral diversity. Else, they favour a unique sector $A$.

The formal proof is in Appendix. There are two differences between the constraints described here and those presented in proposition 2. First, what determines the feasibility of a political equilibrium with sectoral diversity is not anymore the aggregate wages, but the aggregate utility. As can be seen in Figure 4, the two are not identical: the range of values of $m_{B}$ such that aggregate utility is higher with firms active in both sectors is (slightly) larger than the range for which aggregate wages are higher because of the existence of a public good. This difference increases when the valuation of the public good increases. The second difference is that the constraint that all transfers happen via the production of public goods disappears. This means that, in the example we present on Figures 1-4, the political equilibrium is not $m_{B}=0$ anymore, but $m_{B}^{c}$, slightly above $m_{B}(\delta=B)$ (see Figure 4). A crucial assumption stemming from our chosen timing is that there is a joint commitment to the social and industrial policy. Without such commitment, in a democracy, the median voter always prefers an industrial policy favoring sector $A$ for a given level of transfer.

In this example, the "social policy" solves the problem of the impossibility to have firms active in both sectors in a political equilibrium. Moreover, it leads to more sectoral diversity than the market equilibrium without industrial policy. Indeed, $m_{B}^{c}>m_{B}(\delta=B)$, where $m_{B}(\delta=B)$ is both the equilibrium with $f_{B}=0$ and the value that maximizes aggregate wages. Thus, in the equilibrium with transfers, $f_{B}>0$, and the majority of voters of type $a$ is willing to subsidize firms in sector $B$, because they get compensated to do so, and the production of public good is more 
efficient when the tax base is broader. This is not always true. On Figures 6-9 (in appendix) we show a variant of the example on Figures 1-4, with a higher relative bargaining power for firms $\lambda$ and a higher share of majority workers $\alpha$. In that case, even if the aggregate surplus is always higher with firms active in both sectors, there is no social policy that leads to it. The reason is that most of the benefits from sectoral diversity go to firms, so that the aggregate wages are always higher when all firms are active in sector $A$.

The transfers $t_{a}$ and $t_{b}$ considered here are pure interpersonal transfers, and neither depend on the sector in which workers are employed nor on the actual wage perceived by workers. It is thus different from considering distinct linear tax rates for different types of workers $\tau_{a}, \tau_{b}$ or different tax rates in different sectors $\tau_{A}, \tau_{B}$. It is also important to note that the transfer we consider here requires the type of workers to be verifiable. Had workers to self-select into a category, transfers would be conditional upon truthful reporting of workers types. For instance, offering different tax rates in the two sectors $\left(\tau_{A}<\tau_{B}\right)$ would not only affect the distribution of wealth among workers, but it would also affect incentives: $\tilde{m}_{B}$ would become higher as a worker of type $b$ would have less incentives to search for the job in which she is more productive if the tax rate in that sector is higher. The same holds if the linear tax rate for a worker of type $b, \tau_{b}$, increases.

The main policy implication is as follows. Without social policy, the political equilibrium is to protect the old industry and transfer wealth to the workers with news skills through the public good and personal income tax. Once social policy becomes available however, a more efficient equilibrium exists in which the new industry is supported and older workers get monetary transfers to compensate them. Commitment is however crucial for social policy to be possible. Without a joint commitment to the implementation of industrial and social policy, the policy we describe cannot be implemented. This implies that the timing and the institutional commitment are as important to the success of an industrial policy as the content of the policy itself.

\section{Industrial policy with monetary transfers among all players}

Consider now a variant of the above setting, but in which the transfers can also be made between workers and firms. We consider, as above, a head of the household offering a combination of transfers and industrial policy, to be implemented by unanimity among both workers and firms. The total surplus - including firms' profit - is by assumption unambiguously higher with firms active in both sectors than in sector $A$ only, $\alpha \sigma_{a A}+(1-\alpha) \sigma_{b A}<\alpha \sigma_{a A}+(1-\alpha) \sigma_{b B}$ as $\sigma_{b B}>\sigma b A$. 
Proposition 4 When unanimous transfers are possible between workers and firms, voters choose an industrial policy that ensures firms are active in both sectors.

The formal proof is in Appendix. Here, any $m_{B}>\tilde{m}_{B}$ can be part of the equilibrium. In the example presented on Figures 1-4, transfers among workers are sufficient to ensure firms active in both sectors, so the political equilibrium with transfer does not necessarily involve transfers from firms to workers - as we have made no assumption on the preference of the head of the household offering the political deal between workers and firms. However, as firms get higher profits with firms active in both sectors than in sector $A$ only, it is also possible that such transfers arise, depending on the offer made by the head of the household - on which objective function we haven't made any assumption besides the willingness to reach Pareto improvements.

In the case where no agreement was possible with transfer among workers only (section 5) however, the equilibrium now involves firms active in both sectors and a strictly positive transfer from firms to workers (see Figures 6-9 in appendix). It is easy to see from the above results that increasing the possibility of transfers increases the scope for a diverse production structure. When no transfers are possible, the political equilibrium is constrained to maintaining the old sector only unless the gain in wages is so high that transfers through the public good and taxes compensate the losses of the median voter. With transfers among workers, as long as wages are higher, sectoral diversity becomes an equilibrium. Transfers between firms and workers ensure the production structure always displays firms active in both sectors.

\section{Conclusion}

This paper asks the following question: how much coordination between industrial, labor and social policies is needed for the development of innovative sectors making the most of the skills available? We start by making the point that an insufficient bargaining power may deter workers from choosing the sector in which they are the most productive. In turn, firms may refrain from offering jobs in innovative sectors if they don't expect appropriate workers. This creates a vicious circle: a low bargaining power for workers, instead of reducing the firms' production costs in innovative sectors, may end up reducing the supply of appropriately skilled workers. Closing the loop, workers rationally anticipate fewer jobs in these sectors, which further reduces their incentives to choose such sectors.

Failing to address this vicious circle produces secular stagnation similar to the one observed in many OECD as well as developing economies. A look at the current policy debates on the 
need to modernize the economies in Belgium, France or Spain for instance shows that, rather than considering the interactions between the three policies, policymakers tend to focus relatively more on increasing wage flexibility as a complement to industrial policy rather than on the relevance of the distribution of bargaining power and on the transitional costs. Our paper shows that, under common democratic decision processes, this strategy is unlikely to work. Without an explicit management of the transition cost for workers and employers in the old sector, a majority of workers with older skills will continue to protect the older industry, even it means losing the investments in education of the younger generations and impeding the modernization of the economy.

Our model suggests that to produce political support, an efficient industrial policy must subsidize investment in the new sectors, and facilitate the mobility of workers towards these sectors in a labor market in which they are guaranteed to share in the benefits from modernization. The political support also demands an explicit commitment to internalize the transitional cost of the economic transformation. This role should be assigned to a coordinated social policy. Unless this social policy allows for transfers to older workers and support for new industries, democracy is unlikely to deliver the most efficient policy mix.

While our theoretical case does not deal explicitly with the shrinking of the middle class or the increasing gap between the returns to capital and labor and the resulting erosion of the labor share in the national income in economies failing to modernize, these stylized facts are also consistent with our results. Moreover, our discussion of the need to account for the relevance of the distribution of the bargaining power is also consistent with the renewal of the case for profit sharing, for more cooperative production structures and for a restructuring of trade unions' mandate to close the gaps between insiders and outsiders. These solutions are also compatible with the much needed debate on the need to figure out a way of managing upfront the possibly high social transitional costs associated with economic transformation. Our results suggest that this debate is particularly important at a time social policies have been downscaled to control deficits. ${ }^{6}$ Upscaling social policies should be seen as a necessary complement to industrial policy rather than an impediment.

Our results have of course some limitations which deserve some conceptual follow up work. They flow from an approach combining stylized models of the labor market, industrial policy and the voting process. In the labor market, we abstract from frictions stemming from congestion in job search and job posting. Adding this dimension to our model would allow us to specifically model unemployment. We model industrial policy as support for a given sector, but consider that the investment decision of a firm is a discrete choice between two sectors. A more realistic

\footnotetext{
${ }^{6}$ See for instance Vegh and Vuletin (2014).
} 
model would allow for vertical differentiation of the investment. Such differentiation would add an additional dimension of competition among firms, not only for workers but also for innovations. Finally, as our game is static, so is the voting process we study. The old generation considers only its current interest and does not foresee the possible impact of current policy on future outcomes, as for instance pensions. Voters expecting a long retirement and not discounting the future too much might have less vested interests than in our setting.

The policy relevance of our results also deserves some fine tuning since specific implementation details depend on the institutional characteristics of each country. To ensure that coordination is effective and implementable to offset the slow growth and lasting labor market challenges is clearly a local matter. But the paper suggests that, focusing on the interactions between the policies rather than considering them separately would be a step in the right direction under the most common political and institutional contexts. 


\section{Bibliography}

Acemoglu, Daron, “Good jobs versus bad jobs,” Journal of Labor Economics, 2001, 19 (1), 1-21.

_ and Jörn-Steffen Pischke, “The structure of wages and investment in general training," Journal of political economy, 1999, 107 (3), 539-572.

_ and Robert Shimer, "Holdups and efficiency with search frictions," International Economic Review, 1999, 40 (4), 827-849.

Aghion, Philippe, Jing Cai, Mathias Dewatripont, Luosha Du, Ann Harrison, and Patrick Legros, "Industrial policy and competition," American Economic Journal: Macroeconomics, 2015, 7 (4), 1-32.

Albrecht, James W and Bo Axell, “An equilibrium model of search unemployment,” The Journal of Political Economy, 1984, pp. 824-840.

Alder, Simon, Lin Shao, and Fabrizio Zilibotti, "Economic reforms and industrial policy in a panel of Chinese cities," Journal of Economic Growth, 2016, 21 (4), 305-349.

Anderson, Simon $\mathbf{P}$ and Regis Renault, "Pricing, product diversity, and search costs: A Bertrand-Chamberlin-Diamond model," The RAND Journal of Economics, 1999, pp. 719-735.

Arkolakis, Costas, "A unified theory of firm selection and growth," The Quarterly Journal of Economics, 2016, 131 (1), 89-155.

Baghdadi, Leila, Rihab Bellakhal, and Marc-Arthur Diaye, "Financial participation: does the risk transfer story hold in France?," British Journal of Industrial Relations, 2016, 54 (1), 3-29.

Bergstrom, Theodore C, "A fresh look at the rotten kid theorem-and other household mysteries," Journal of Political Economy, 1989, 97 (5), 1138-1159.

Brueckner, Jan K, Jacques-François Thisse, and Yves Zenou, "Local labor markets, job matching, and urban location," International Economic Review, 2002, 43 (1), 155-171. 
Castanheira, Micael and Georges Siotis, "Regions in Europe: Sisyphus or Phoenix?," in Paul Magnette and Eric Remacle, eds., Le nouveau modÃlle europÃl'en. Les politiques internes et externes, 2004, pp. 47-62.

Cerqua, Augusto and Guido Pellegrini, "Do subsidies to private capital boost firms' growth? A multiple regression discontinuity design approach," Journal of Public Economics, 2014, 109, $114-126$.

Comin, Diego and Bart Hobijn, "Lobbies and technology diffusion," The Review of Economics and Statistics, 2009, 91 (2), 229-244.

Criscuolo, Chiara, Ralf Martin, Henry G Overman, and John Van Reenen, “The causal effects of an industrial policy," 2016.

Decreuse, Bruno and Tanguy Van Ypersele, "Housing market regulation and the social demand for job protection," Journal of Public Economics, 2011, 95 (11-12), 1397-1409.

Farrell, Joseph and Robert Gibbons, "Cheap talk about specific investments," JL Econ. \& Org., $1995,11,313$.

Gall, Thomas, Patrick Legros, and Andrew Newman, "The timing of education," Journal of the European Economic Association, 2006, 4 (2-3), 427-435.

Hamilton, Jonathan, Jacques-Francois Thisse, and Yves Zenou, "Wage competition with heterogeneous workers and firms," Journal of Labor Economics, 2000, 18 (3), 453-472.

Helsley, Robert W and William C Strange, "Matching and agglomeration economies in a system of cities," Regional Science and Urban Economics, 1990, 20 (2), 189-212.

Hodler, Roland, "Industrial policy in an imperfect world," Journal of Development Economics, 2009, $90(1), 85-93$.

Hosios, Arthur J, "On the efficiency of matching and related models of search and unemployment," The Review of Economic Studies, 1990, 57 (2), 279-298.

ICF, 2007-2013 Ex-post evaluation of ESF investment into human capital,, Report for the European Commission, Directorate-General Employment, Social Affairs and Inclusion., 2015.

Kruse, Douglas L, Richard B Freeman, and Joseph R Blasi, Shared capitalism at work: Employee ownership, profit and gain sharing, and broad-based stock options, University of Chicago Press, 2010. 
Krusell, Per and Jose-Victor Rios-Rull, "Vested interests in a positive theory of stagnation and growth," The Review of Economic Studies, 1996, 63 (2), 301-329.

Marimon, Ramon and Fabrizio Zilibotti, "Unemployment vs. mismatch of talents: reconsidering unemployment benefits," The Economic Journal, 1999, 109 (455), 266-291.

Mortensen, Dale T and Christopher A Pissarides, "Job creation and job destruction in the theory of unemployment," The review of economic studies, 1994, 61 (3), 397-415.

_ and _ , "Job reallocation, employment fluctuations and unemployment," Handbook of macroeconomics, 1999, 1, 1171-1228.

Papageorgiou, Theodore, "Learning your comparative advantages," Review of Economic Studies, 2014, 81 (3), 1263-1295.

Rodrik, Dani, “Industrial policy: don't ask why, ask how," Middle East Development Journal, 2009, $1(01), 1-29$.

Şahin, Ayşegül, Joseph Song, Giorgio Topa, and Giovanni L Violante, "Mismatch unemployment," The American Economic Review, 2014, 104 (11), 3529-3564.

Saint-Paul, Gilles, “The political economy of employment protection," Journal of political economy, 2002, $110(3), 672-704$.

Shimer, Robert and Lones Smith, "Matching, search, and heterogeneity," Advances in Macroeconomics, 2001, 1 (1).

Silos, Pedro and Eric Smith, "Human capital portfolios," Review of Economic Dynamics, 2015, $18(3), 635-652$.

Vegh, Carlos A and Guillermo Vuletin, "Social implications of fiscal policy responses during crisess," National Bureau of Economic Research, 2014.

Wilemme, Guillaume, “Optimal Taxation to Correct Job Mismatching,” 2017.

Wolinsky, Asher, "True monopolistic competition as a result of imperfect information," The Quarterly Journal of Economics, 1986, 101 (3), 493-511. 
Sector A, $m_{A}=8$

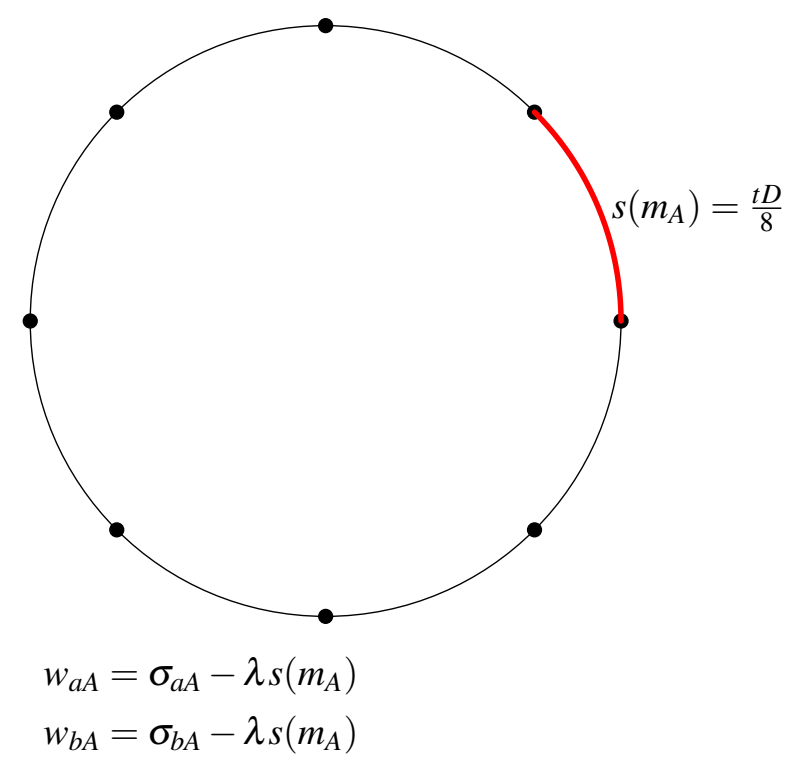

Sector B, $m_{B}=4$

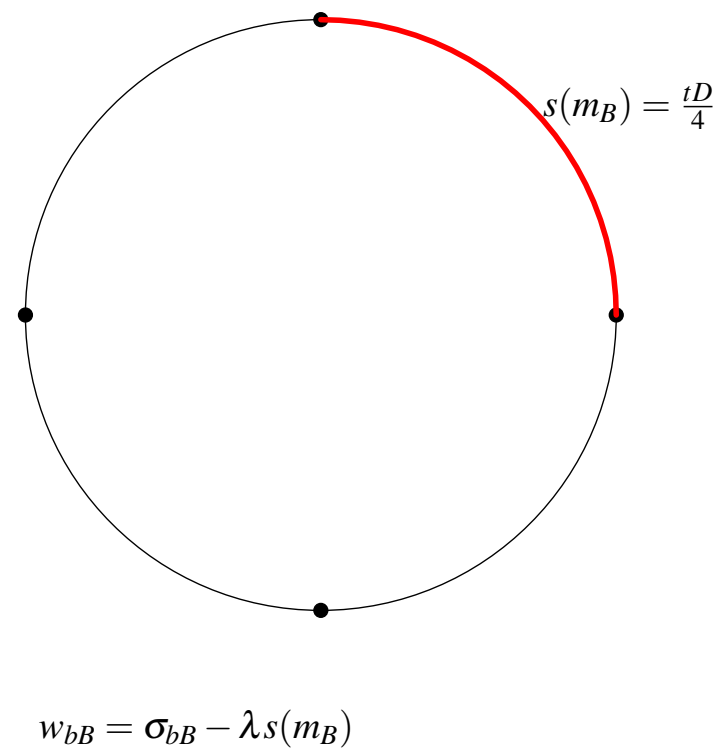

Figure 6: A Salop location model with linear transportation cost $t$ and circumference $D, \lambda=\frac{1-\beta}{\beta}$.

\section{Appendix A: micro-foundation of the $s$ function}

Perhaps the simplest form of such differentiation would correspond to firms located symmetrically on a Salop circle of circumference $D$, with travel cost $s$. With linear transportation costs $t>0$, our function would then be $s\left(m_{\chi}\right)=t D / m_{\chi}$ with $s^{\prime}=-t D / m_{\chi}^{2}$ and $s^{\prime \prime}=2 t D / m_{\chi}^{3}$. Alternatively, one could consider that a worker browses firm sequentially and randomly (in the spirit of Wolinsky, 1986 and Anderson and Renault, 1999), and finds a firm active in sector $\chi$ with probability $m_{\chi} / M$. Hence, with a linear search cost of $s$ the expected total search cost of finding a firm in sector $\chi$ is given by $s\left(m_{\chi}\right)=\frac{s M}{m_{\chi}}$ (Denote by $\gamma_{i}=m_{\chi} / M$, the expected search cost is $s(\gamma)=s \sum_{i=0}^{\infty}\left(1-\gamma_{i}\right)^{i}=$ $\frac{s}{\gamma}=\frac{s M}{m_{\chi}}$.), with $s^{\prime}=-s M / m_{\chi}^{2}$ and $s^{\prime \prime}=2 s M / m_{\chi}^{3}$. What we need for our results to hold is the following: it is less costly for a worker to join another firm in sector $\chi$ if there are more firms in sector $\chi$.

We provide on Figure 6 an example with firms symmetrically located on a Salop circle, with $m_{A}=8$ firms in sector A and $m_{B}=4$ in sector B. The choice of a worker of type $b$ is to trade off a higher match value in sector $B$ with a higher market power in sector $A$.

\section{Appendix B: formal proofs}

\section{Proof of Lemma 1}

Proof. A worker of type $b$ is active in sector $B$ if and only if $w_{b B}>w_{b A}$, corresponding to the condition in the proposition. In terms of relative bargaining power, this condition rewrites $\lambda<$ $\frac{\sigma_{b B}-\sigma_{b A}}{s\left(m_{B}\right)-s\left(m_{A}\right)}=\lambda^{s}\left(m_{B}\right)$, as $m_{A}=M-m_{B}$. 


\section{Proof of Lemma 2.}

Proof. If $\delta=b$, the number of firms active in sector $A$ is equal to $m_{A}(\delta=B)$, with $m_{B}=M-m_{A}$ solving

$$
\frac{\alpha}{1-\alpha}=\frac{m_{A}(\delta=B)}{m_{B}(\delta=B)} \frac{s\left(m_{B}(\delta=B)\right)}{s\left(m_{A}(\delta=B)\right)} .
$$

As $s^{\prime}<0$ and $s^{\prime \prime}>0, m_{A}(\delta=B) \in[M / 2, \alpha M]$.

\section{Proof of Proposition 1}

Proof. As all firms have the same expected profit, at equilibrium.

$$
\pi^{*}(\boldsymbol{\delta}=B)=\lambda \frac{\alpha s\left(m_{A}(\delta=B)\right)+(1-\alpha) s\left(m_{B}(\delta=B)\right)}{M}>\lambda \frac{s(M)}{M}=\pi^{n s} .
$$

Hence, if for $m_{A}(\delta=B), m_{B}(\delta=B)$ workers go to their best sector, it is the equilibrium of the game. Using lemma 1 , this condition rewrites $\lambda<\frac{\sigma_{b B}-\sigma_{b A}}{s\left(m_{B}(\delta=B)\right)-s\left(m_{A}(\delta=B)\right)}=\lambda^{s}\left(m_{B}(\delta=B)\right)$.

\section{Proof of Lemma 3}

Proof. The minimum number of firms in sector $\tilde{m}_{B}$ follows directly from rewriting the condition in lemma 5 as $s\left(\tilde{m}_{B}\right)-s\left(M-\tilde{m}_{B}\right)=\frac{\sigma_{b B}-\sigma_{b A}}{\lambda}$. Replacing by $\tilde{m}_{B}$ in (6) and adding the constraint $\tilde{f}_{A}=\frac{-\tilde{m}_{B}}{M-\tilde{m}_{N}} \tilde{f}_{B}, \tilde{f}_{b}$ solves

$$
\tilde{f}_{B}=\lambda \frac{\alpha \tilde{m}_{B} s\left(M-\tilde{m}_{B}\right)-(1-\alpha)\left(M-\tilde{m}_{B}\right) s\left(\tilde{m}_{B}\right)}{M-2 \tilde{m}_{B}} .
$$

From (7), we see that $\tilde{f}_{B}>0$ if and only if $\lambda>\lambda^{s}$.

\section{Proof of Lemma 4}

Proof. A majority of voters $\alpha$ is of type $a$, with identical preferences. As we assume sincere voting, a voter of type $a$ chooses policy $\psi$ over policy $\psi^{\prime}$ if and only if $u(\psi)>u\left(\psi^{\prime}\right)$. As the objective of parties is purely to be elected, by standard median voter arguments, both choose an identical platform $\psi^{*}$ that maximizes the utility of a voter of type $a$, and both parties are elected with equal probability $1 / 2$. Else, there would always be a platform $\psi^{\prime}$ with $u\left(\psi^{\prime}\right)>u(\psi *)$ such that the party offering $\psi^{\prime}$ wins with probability 1 .

To determine $\psi^{*}$, one needs to compare the local optimum of two subgames. The first one is $m_{B}=0$ and corresponds to the equilibrium with firms active in sector $A$ only and taxe rate $\tau^{*}(0)$. The second corresponds to $m_{B}>\tilde{m}_{B}$ and corresponds to the equilibrium with firms active in both sectors and a tax function $\tau^{*}\left(m_{B}\right)$. The local maximum is thus the value of $m_{B} \in\left\{\tilde{m}_{B}, M / 2\right)$ that maximizes $u_{a}$. We denote this value by $\bar{m}_{B}$. The political equilibrium of the game is thus the maximum of the two subgames. 


\section{Proof of Proposition 2}

Proof. First, we want to show that aggregate wages higher with two active sectors than with sector $A$ only is a necessary condition for the median voter to choose an industrial policy that ensures firms are active in both sectors. This means that there must exist at least one value of $m_{B} \geq \tilde{m}_{B}$ such that

$$
\left.(1-\alpha)\left(\sigma_{b B}-\sigma_{b A}\right)>\lambda\left(\alpha s\left(M-m_{B}\right)+(1-\alpha) s\left(m_{B}\right)\right)-s(M)\right)
$$

By assumption, $s\left(m_{A}\right)>s(M)$, for all $m_{A}<M$. Define by $w_{a A}(\delta=B)$ the wage of a worker of type $a$ with firms active in both sectors and $w_{a A}(\delta=A)$ without it. Fir any industrial and tax policy, if the market equilibrium is such that there is no sectoral diversity, it is always true that $w_{a A}(\delta=B)<w_{a A}(\delta=A)$. If there is no value of $m_{B} \geq \tilde{m}_{B}$ that satisfies (15), it means that $\alpha w_{a A}(\delta=B)+(1-\alpha) w_{b B}(\delta=B)<\alpha w_{a A}(\delta=A)+(1-\alpha) w_{b A}(\delta=A)$. Thus, for all $\tau$, $u_{a}(\delta=B)<u_{a}(\delta=A)$ : as the median voter is of type $a$, she always chooses a value of $f_{B}<\tilde{f}_{B}$ to ensure no firm enters this sector.

Second, assume there exists values of $m_{B} \geq \tilde{m}_{B}$ that satisfies (15). Define the set of such values by $\mu_{b}$. The equilibrium policy is the one that maximizes the surplus of the median voter. We first rewrite the optimal taxation in terms of $m_{B}$ only, for values of $m_{B} \in \mu_{B}$ so that firms are active in both sectors

$$
\begin{array}{r}
\tau_{d}^{*}\left(m_{B}\right)=v^{\prime-1}\left(\frac{\sigma_{a A}-\lambda s\left(M-m_{B}\right)}{\alpha\left(\sigma_{a A}-\lambda s\left(M-m_{B}\right)\right)+(1-\alpha)\left(\sigma_{b B}-\lambda s\left(m_{B}\right)\right)}\right) \\
\frac{1}{\alpha\left(\sigma_{a A}-\lambda s\left(M-m_{B}\right)\right)+(1-\alpha)\left(\sigma_{a A}-\lambda s\left(m_{B}\right)\right)}
\end{array}
$$

In the examples we use through the figures, with $v(G)=g \sqrt{G}$,

$$
\tau_{d}^{*}\left(m_{B}\right)=\frac{g^{2}\left(M-m_{B}\right)\left(M\left(m_{B}\left(\sigma_{a A}+\sigma_{b B}\right)-\lambda s\right)-m_{B}^{2}\left(\sigma_{a A}+\sigma_{b B}\right)\right)}{4 m_{B}\left(\sigma_{a A}\left(m_{B}-M\right)+\lambda s\right)^{2}} .
$$

The equilibrium policy conditional on $m_{B} \in \mu_{B}$ solves

$\bar{m}_{B, d}=\arg \max _{m_{B} \in \mu_{b}}\left(1-\tau^{*}\left(m_{B}\right)\right)\left(\sigma_{a A}-s\left(M-m_{B}\right)\right)+v\left(\tau^{*}\left(\alpha\left(\sigma_{a A}-s\left(M-m_{B}\right)\right)+(1-\alpha)\left(\sigma_{b B}-s\left(m_{B}\right)\right)\right)\right.$.

In the case with firms active in sector $A$ only, the equilibrium tax is given by

$$
\tau_{n d}^{*}=v^{\prime-1}\left(\frac{\sigma_{a A}-\lambda s(M)}{\alpha \sigma_{a A}+(1-\alpha) \sigma_{b A}-\lambda s(M)}\right) \frac{1}{\alpha \sigma_{a A}+(1-\alpha) \sigma_{b A}-\lambda s(M)} .
$$

The relationship between $\tau_{n d}^{*}$ and $\tau_{d}^{*}$ is not clear. As $w_{a}^{d}<w_{a}^{n d}$ and $\alpha w_{a}^{d}+(1-\alpha) w_{b}^{d}>\alpha w_{a}^{n d}+(1-$ $\alpha) w_{b}^{n d}$, it is clear that $G^{d}>G^{n d}$ (lower marginal cost of taxation and higher marginal revenue), but not clear that $\tau^{n d}<\tau^{d}$ (depends on the slope of $v$ ). Whether a worker of type $a$ prefers firms to be active in two sectors therefore boils down to whether she values the public good sufficiently, and 
whether the gains from the higher revenues of the second groups are thus sufficiently high, this is whether

$$
v\left(G^{n d}\right)+\left(1-\tau_{n d}^{*}\right) w_{a}^{n d}>v\left(G^{d}\right)+\left(1-\tau^{d}\right) w_{a}^{d} .
$$

For instance, if $v(G)=0$, the majority voters never want to have two active sectors. We want now to prove that in the special cases of linear transportation costs or linear random search costs the political equilibrium always yields $m_{b}, m_{B}(\boldsymbol{\delta}=B)$. To see this, consider the most extreme case, in which workers care only about the public good, corresponding to the maximum share of firms in sector $B$ a worker of type $a$ is willing to have. This could for instance be a function $v(G)=g \eta(g)$ with $\eta(g)$ increasing and $g \rightarrow \infty$. In this case, $\tau^{*}(.) \rightarrow 1$, so that the worker of type $b$ votes for the policy that maximizes aggregate wages. In the special cases of linear transportation costs or linear random search costs, this maximization problem can be rewritten when there is sectoral diversity as

$$
\max _{m_{B}} \alpha\left(\sigma_{a A}-\frac{s M}{M-m_{B}}\right)+(1-\alpha)\left(\sigma_{b B}-\frac{s M}{m_{B}}\right),
$$

in the linear sequential search, and $\max _{m_{B}} \alpha\left(\sigma_{a A}-\frac{t D}{M-m_{B}}\right)+(1-\alpha)\left(\sigma_{b B}-\frac{t D}{m_{B}}\right)$, on a Salop circle, which both have an identical solution:

$$
\frac{\alpha}{\left(M-m_{B}\right)^{2}}=\frac{1-\alpha}{m_{B}^{2}}
$$

In the special cases of linear transportation costs or linear random search costs, the equilibrium number of sector $B$ when there is sectoral diversity can be rewritten as

$$
\frac{\alpha}{M-m_{B}} \frac{\lambda s M}{M-m_{B}}=\frac{1-\alpha}{m_{B}} \frac{\lambda s M}{m_{B}},
$$

in the linear sequential search, and $\frac{\alpha}{M-m_{B}} \frac{\lambda t D}{M-m_{B}}=\frac{1-\alpha}{m_{B}} \frac{\lambda t D}{m_{B}}$, on a Salop circle, which both are equivalent to:

$$
\frac{\alpha}{\left(M-m_{B}\right)^{2}}=\frac{1-\alpha}{m_{B}^{2}}
$$

As this is the most extreme case - the median voter only cares about the aggregate wages, there is no political equilibrium such that $\bar{m}_{B}>m_{B}^{*}$.

\section{Proof of Proposition 3}

Proof. As monetary transfers among workers are possible, and as utility is quasi-linear in money, the only Pareto-efficient equilibrium is the one that maximizes aggregate utility. As there is a unique equilibrium linear tax $\tau$ and sectoral diversity for each industrial policy $f$, and as by lemma 3 any $m_{B} \geq \tilde{m}_{B}$ can be induced by an industrial policy, selecting an equilibrium aggregate utility is equivalent to selecting a $m_{B} \in\left\{0,\left[\tilde{m}_{B}, M / 2\right]\right\}$. Denote by $m_{B}^{c}$ the number of firms in sector $B$ 
maximizing aggregate utility conditional on workers searching, $m_{B}^{c}=\arg \max _{m_{B} \geq \tilde{m}_{B}} \alpha u_{a}\left(m_{B}\right)+$ $(1-\alpha) u_{B}\left(m_{B}\right)$. By definition, if the equilibrium share of firms in sector $B$ found in Section 4 is such that that firms are active in two sectors, $m_{B}^{c}$ yields strictly higher aggregate worker utility. Hence, there exists transfers such that a policy $f$ that yields $m_{B}^{c}$ can be unanimously accepted, and such a policy exists by lemma 3 . The same applies if the equilibrium share of firms in sector $B$ found in Section 4 is such that that firms are active in sector $A$ only. Hence, $m_{B}^{c}$ is the equilibrium number of firms in sector $B$ is aggregate worker utility is higher with $m_{B}^{c}$ than with $m_{B}=0$.

\section{Proof of Proposition 4}

Proof. As monetary transfers among all players are possible, as utility is quasi-linear in money and firms maximize profit, the aggregate surplus is always maximized in the presence of two active sectors. For the same reasons as in Proposition 3, a diverse equilibrium can always be reached. Because all types of transfers are possible, any $m_{B} \in\left[\tilde{m}_{B}, M / 2\right]$ is an equilibrium.

\section{Appendix C: Pareto-improving increases in workers' bargaining power}

In the following, we identify conditions for an increase in workers' relative bargaining power to benefit all types of players. We provide a condition (see Proposition 5) for such an increase to be Pareto improving.

\section{Firms}

We have shown in Section 2.3 that employers always prefer, for a given bargaining power, workers to to be active in both sectors. This is because it gives them higher market power: the expected profit of a firm in a non-diverse economy $\left(m_{A}=M\right)$ is equal to $\pi_{\delta=A}=\lambda \frac{s(M)}{M}$, while the expected profit in a diverse economy is $\pi_{\delta=B}=\lambda \frac{\alpha s\left(m_{A}(\delta=B)\right)+(1-\alpha) s\left(m_{B}(\delta=B)\right)}{M}$ with $s\left(m_{B}(\delta=B)\right)>$ $s\left(m_{A}(\delta=B)\right)>s(M)$, as from Lemma 2 a strict majority of the employers are active in the old sector $A$ in a diverse economy.

We illustrate equilibrium firms' profit in figure 12. While the expected profit in a given equilibrium is increasing in firms' (relative) bargaining power $\lambda$, there is a discontinuity at $\lambda^{s}$. Hence, for all $\lambda>\lambda^{s}$, firms are better off with a smaller bargaining power $\lambda^{\prime}$ if there exists a $\lambda^{\prime}<\lambda^{s}$ such that

$$
\begin{aligned}
\pi_{\delta=B}^{*}\left(\lambda^{\prime}\right) & >\pi_{\delta=A}^{*}(\lambda) \\
\lambda^{\prime} & >\lambda \frac{s(M)}{\alpha s\left(m_{A}(\delta=B)\right)+(1-\alpha) s\left(m_{B}(\delta=B)\right)}=\lambda^{f}(\lambda) .
\end{aligned}
$$

The function $\lambda^{f}(\lambda)$ therefore gives the maximum "sacrifice" of relative bargaining power a firm is willing to make - compared to a reference point $\lambda$ - in exchange for higher sectoral diversity. 


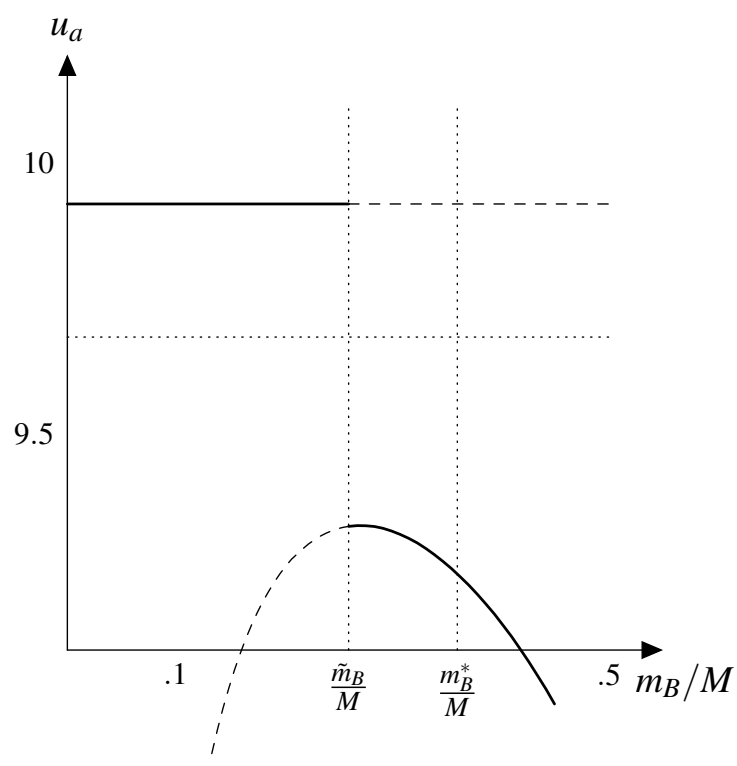

Figure 6: Utility of a worker of the majority type $a$

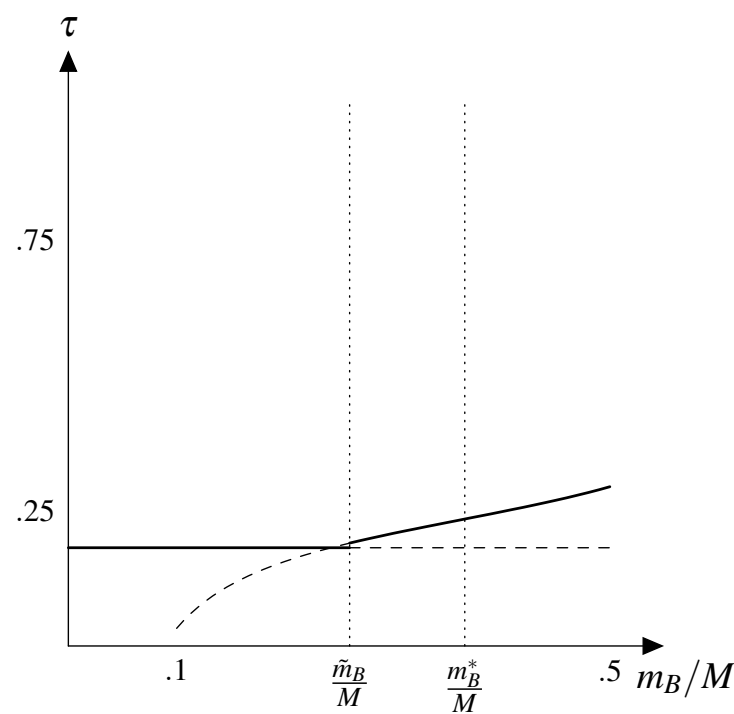

Figure 8: Equilibrium tax rate $\tau$

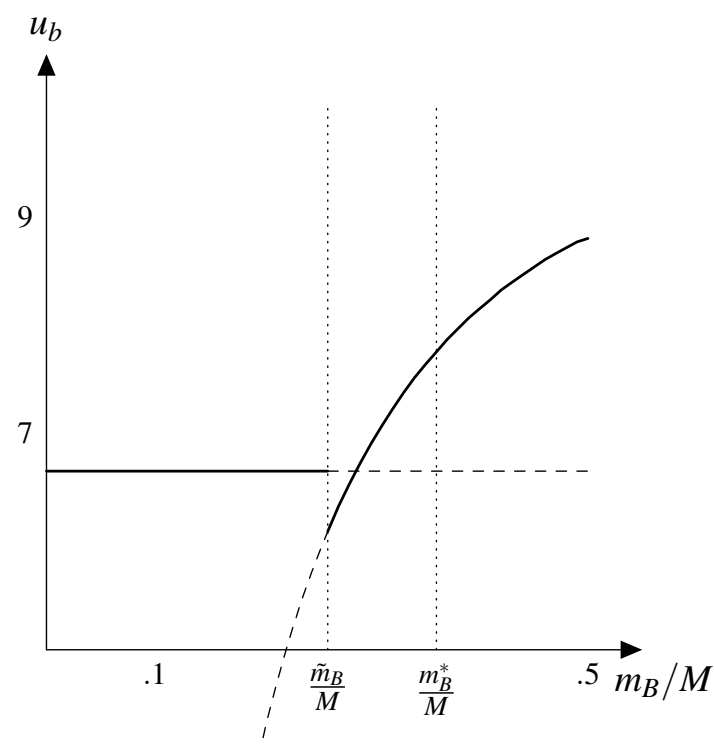

Figure 7: Utility of a worker of the minority type $b$

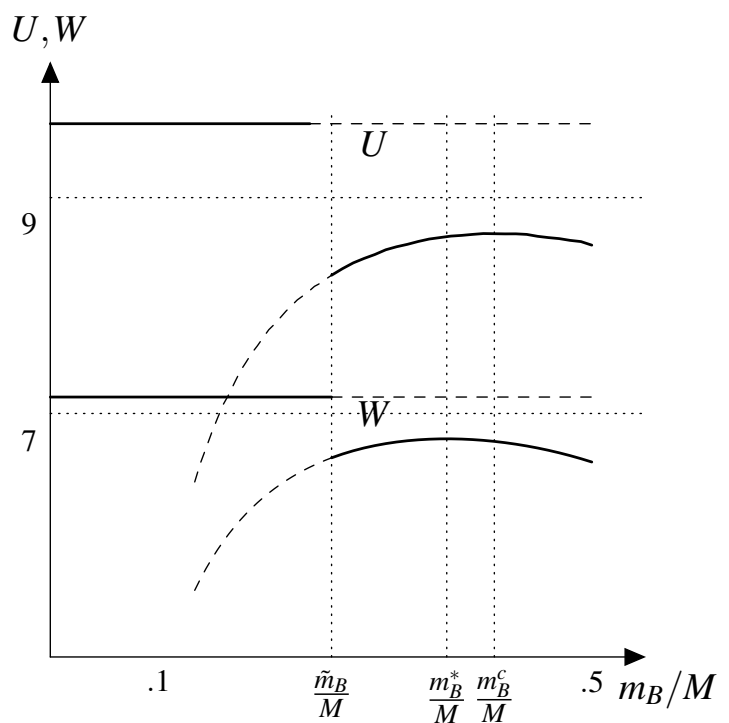

Figure 9: Aggregate worker utility $U$ and wages $W$

Political equilibrium, $\lambda=.4, M=15, s=60, \sigma_{a A}=\sigma_{b B}=10, \sigma_{a B}=8, \sigma_{b A}=6, \alpha=.75$, $v(G)=2 \sqrt{G}$. 


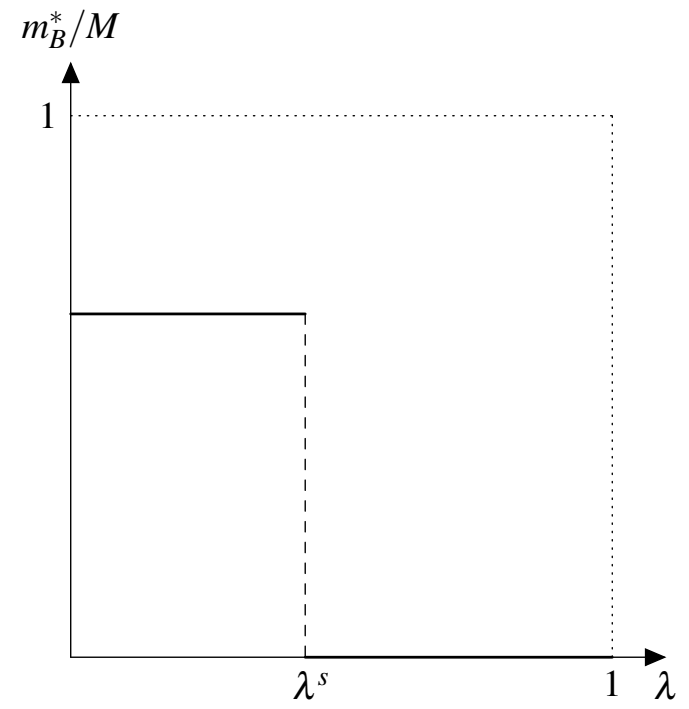

Figure 11: Share of the firms active in Sector $B$

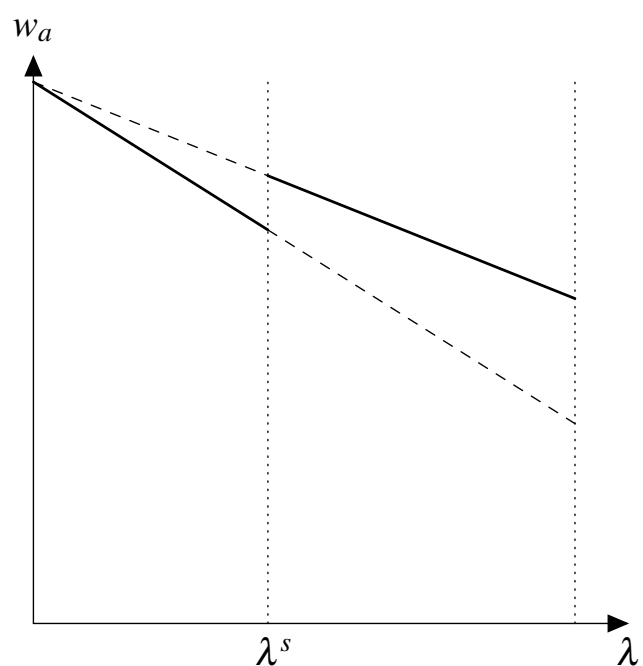

Figure 13: Expected wage of a worker of type $a$

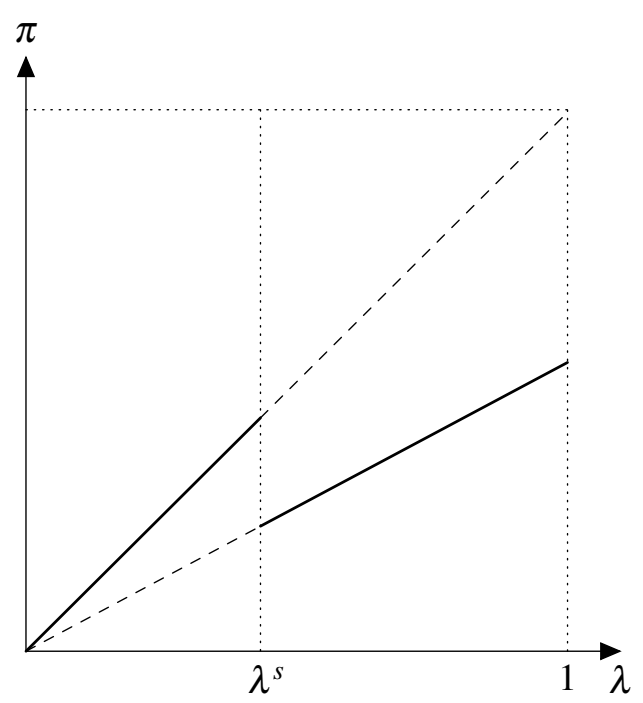

Figure 12: Expected firm profit

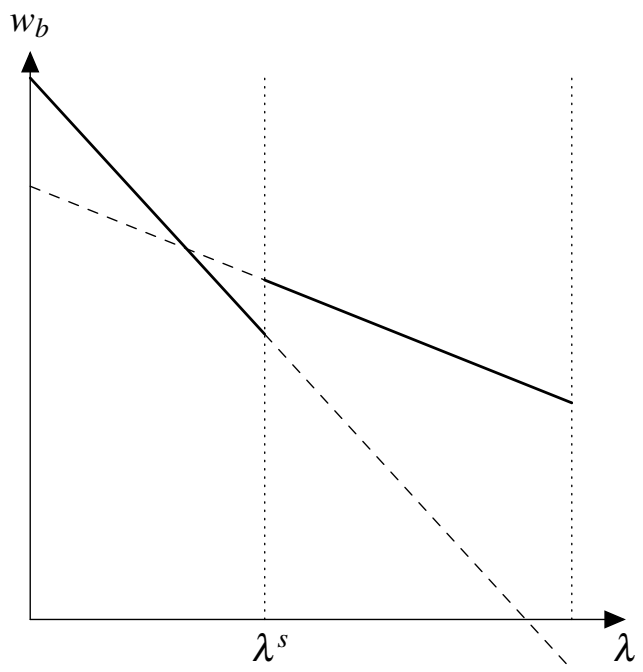

Figure 14: Expected wage of a worker of type $b$

Equilibrium outcomes, for $M=15, s=60, \sigma_{a A}=\sigma_{b B}=10, \sigma_{a B}=\sigma_{b A}=8, \alpha=.75$. 


\section{Workers of type $a$}

For a given $\lambda$, a worker of the majority type loses from higher sectoral diversity. The reason is that such a worker gets the same match productivity with and without sectoral diversity, but the distance to the next closest firm becomes higher. More sectoral diversity for a worker of the majority type simply means a lower wage for the same job, as the market structure is now more diverse. We illustrate the equilibrium wage of workers of type $a$ on Figure 13. There also is a discontinuity at $\lambda^{s}$, but this time corresponding to a discrete loss of wage due to the higher market power of firms.

Hence, for all $\lambda>\lambda^{s}$, workers of the majority type $a$ are better off with a diverse production and a higher relative bargaining power $\lambda^{\prime}<\lambda^{s}$ only if this increase in workers' bargaining power is sufficient to compensate for the lower outside option, this is

$$
\lambda^{\prime}<\lambda \frac{s(M)}{s\left(m_{A}^{*}(\delta=B)\right)}=\lambda^{a}(\lambda)
$$

The function $\lambda^{a}(\lambda)<\lambda$ is thus the maximum relative bargaining power - compared to a reference point $\lambda$ - a worker of the majority type $b$ is willing to accept to give to firms to be compensated for the loss of market power due to higher sectoral diversity.

\section{Workers of type $b$}

Finally, the wage of workers of the minority type $b$ is represented on figure 14 . The discontinuity at $\lambda^{s}$ is different from workers of type $a$ as the change in equilibrium corresponds to switching to more productive activities. However, at $\lambda^{s}$, the wages of the minority type also discretely decrease, as what determines the existence of a diverse equilibrium is whether minority workers choose their best sector given that there are two active sectors. Hence, they compare a wage that is lower than their productivity by an amount of $\lambda s\left(m_{B}(\delta=B)\right)$ in sector B to $\lambda s\left(m_{A}(\delta=B)\right)$ in sector $A$, albeit with a lower productivity. Whether the wage of a worker of type $b$ in a firm active in sector $B$ when there are two active sectors - $\sigma_{b B}-\lambda s\left(m_{B}(\delta=B)\right)$ - is higher than the wage of this worker in sector $A$ when there are two active sectors, $\sigma_{b A}-\lambda s\left(m_{A}(\delta=B)\right)$ depends on the relative importance of the match value and of the market power. If firms are active in the two sectors, we cannot observe the counter factual of workers of type $b$ moving to sector $A$ without sectoral diversity, and receive a wage lower than their productivity by an amount of $\lambda s(M)<\lambda s\left(m_{A}(\delta=B)\right)$ only. Hence revealed preferences are not sufficient to conclude that workers of type $b$ prefer two active sectors.

Workers of type $b$ are thus better off with a relative bargaining power of firms $\lambda^{\prime}$ and a diverse production structure than without sectoral diversity and with a relative bargaining power of firms equal to $\lambda$ if

$$
\lambda^{\prime}<\frac{\sigma_{b B}-\sigma_{b A}}{s\left(m_{B}(\delta=B)\right)}+\lambda \frac{s(M)}{s\left(m_{B}(\delta=B)\right)}=\lambda^{b}(\lambda)
$$

The following lemma shows that this condition is however never binding when considering Pareto optimality. 
Lemma 5 If a relative bargaining power $\lambda^{\prime}<\lambda^{\text {s }}$ corresponds to a diverse economic structure, then if it makes workers of the majority type a better off than a given bargaining power corresponding to a non-diverse economy, it also makes workers of the minority type b better off, $\lambda^{b}(\lambda)>\lambda^{a}(\lambda)$.

Proof. Simple arithmetic shows that $\lambda^{b}(\lambda)>\lambda^{a}(\lambda)$ is equivalent to $\lambda^{\prime}<\frac{\sigma_{b B}-\sigma_{b A}}{s\left(m_{B}(\delta=B)\right)-s\left(m_{A}(\delta=B)\right)}=$ $\lambda^{s}$.

The above lemma means that if workers of the majority type are made better off with two active sectors, so are workers of the minority type. It does not mean however that workers of type $b$ always prefer two active sectors. It can be the case that the gain in market power for the firms outweighs the gain in productivity, but that once $m_{B}(\delta=B)$ firms are active in sector $B$, workers of type $b$ prefer this sector (while they would have preferred all the firms to be active in sector $A$ ). However, if workers of the majority type $a$ prefer two active sectors, so do the ones of the minority type $b$.

\section{Higher bargaining power for workers can be Pareto improving}

Given that the total surplus is higher with than without sectoral diversity, it is natural to think that a social planner able to choose the respective bargaining powers could make everyone better off. As firms are unambiguously better off with two active sectors, there is a trade-off for them between their bargaining power and sectoral diversity. In particular, it is possible to improve everyone's surplus by increasing worker's bargaining power if it is not initially too low.

Proposition 5 For any $\lambda \in\left(\lambda^{s}, \bar{\lambda}\right)$, firms are active in sector $A$ only. However, there exists a $\lambda^{\prime}<\lambda^{s}$ that is Pareto improving.

Proof. As $\gamma \in(1 / 2, \alpha)$, it follows that $\lambda^{f}(\lambda)<\lambda^{a}(\lambda)$ for all $\lambda$. Hence, by lemma 5 , any $\lambda^{\prime} \in$ $\left(\lambda^{f}(\lambda), \lambda^{a}(\lambda)\right)$ is Pareto improving. However, it still needs to be the case that such $\lambda<\lambda^{s}$ for firms to be active in both sector in equilibrium. Such a $\lambda^{\prime}$ exists if $\lambda^{f}(\lambda)<\lambda^{\prime}$, equivalent to $\lambda<\frac{\alpha}{\gamma^{*}} \frac{s\left(m_{A}(\delta=B)\right)}{s(M)} \lambda^{s}=\underline{\lambda}$, with $\underline{\lambda}>\lambda^{s}$ as $\gamma<\alpha$.

The above result shows that increasing workers bargaining power can be Pareto improving if the initial relative bargaining power of firms is below a threshold $\bar{\lambda}$. In theory, if $\lambda$ were contractible, for all $\lambda \in\left(\lambda^{s}, \bar{\lambda}\right)$, it would be possible to a social planner, modeled as the head of a household in Bergstrom (1989), to offer a new bargaining power $\lambda^{\prime}<\lambda^{s}$ to workers and firms, and such a new bargaining power would be unanimously accepted. We illustrate this proposition on figure 15: for all value of $\lambda \in\left(\lambda^{s}, \bar{\lambda}\right)$ (on the $\mathrm{X}$-axis) we provide the minimum value of $\lambda<\lambda^{s}$ that firms are willing to accept $\lambda_{f}$, below the maximum value that a worker of type a is willing to accept $\lambda_{a}$. By lemma 5 , if both workers of type $a$ and firms are willing to accept a new bargaining power, so do workers of type $b$. For values of $\lambda>\bar{\lambda}$, the initial bargaining power of firms is too large for them to accept a deal that involves $\lambda<\lambda^{s}$. For values of $\lambda<\lambda^{\prime}$, sectoral diversity is already the equilibrium, so that firms have nothing to gain from accepting a lower bargaining power. 


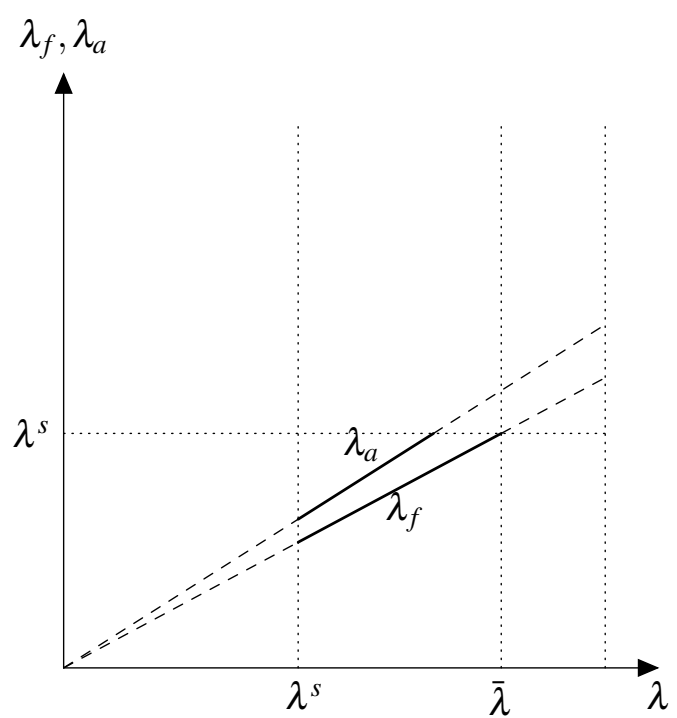

Figure 15: Illustration of Proposition 5, for $M=15, s=60, \sigma_{a A}=\sigma_{b B}=10, \sigma_{a B}=\sigma_{b A}=8$, $\alpha=.75$. 